\title{
Review
}

\section{A Systematic Review of Impulse Control Disorders in Parkinson's Disease}

\author{
Mette Buhl Callesen ${ }^{\mathrm{a}, \mathrm{b}}$, Jørgen Scheel-Krüger ${ }^{\mathrm{b}}$, Morten L. Kringelbach ${ }^{\mathrm{b}, \mathrm{c}}$ and Arne Møller ${ }^{\mathrm{a}, \mathrm{b}}$ \\ ${ }^{a}$ Department of Nuclear Medicine and PET-Centre, Aarhus University Hospital, Aarhus, Denmark \\ ${ }^{\mathrm{b}}$ Center of Functionally Integrative Neuroscience, Aarhus University, Aarhus, Denmark \\ ${ }^{\mathrm{c}}$ Department of Psychiatry, Oxford University, $U K$
}

\begin{abstract}
Throughout the past decade it has been recognized that dopaminergic medication administered to remedy motor symptoms in Parkinson's disease is associated with an enhanced risk for impulse control disorders and related compulsive behaviors such as hobbyism, punding, and the dopamine dysregulation syndrome. These complications are relatively frequent, affecting 6-15.5\% of patients, and they most often appear, or worsen, after initiation of dopaminergic therapy or dosage increase. Recently, impulse control disorders have also been associated with subthalamic nucleus deep brain stimulation. Here we present a systematic overview of literature published between 2000 and January 2013 reporting impulse control disorders in Parkinson's disease. We consider prevalence rates and discuss the functional neuroanatomy, the impact of dopamine-serotonin interactions, and the cognitive symptomatology associated with impulse control disorders in Parkinson's disease. Finally, perspectives for future research and management of impulse control disorders in Parkinson's disease are discussed.
\end{abstract}

Keywords: Impulse control disorders, Parkinson disease, dopamine, serotonin, neuroanatomy, decision making

\section{INTRODUCTION}

Parkinson's disease (PD) is a progressive neurodegenerative disorder associated with a dopamine deficiency in the substantia nigra zona compacta and the ventral tegmental area in the midbrain causing abnormalities in movement, behavior, cognition, and emotion. Based on observations, James Parkinson first described the disorder as the "shaking palsy" in 1817. At that time, the senses and intellect of patients suffering from PD were believed to be unaffected by the disease [1]. Half a century later this assumption was revised by "the father of modern neurology" the French neurologist, Jean-Martin Charcot (1825-93), who

\footnotetext{
*Correspondence to: Mette Buhl Callesen, Department of Nuclear Medicine and PET-Centre, Aarhus University Hospital, Noerrebrogade 44, Building 10 G, 8000 Aarhus C, Denmark. Tel.: +45 78464405; E-mail: buhl@pet.auh.dk.
}

suggested that the patients' state of mind is altered as the disease progresses. Nevertheless, in the general clinic, PD is still largely considered to be a movement disorder characterized by cardinal motor symptoms. According to the UK Brain Bank criteria for PD, presence of bradykinesia accompanied by at least one of the following: resting tremor, muscular rigidity, or postural instability, are required for a diagnosis of PD. Furthermore, at least three supportive criteria including: unilateral onset, excellent response to levodopa, resting tremor, severe levodopa-induced chorea, progressive disorder, levodopa response for over 5 years, persistent asymmetry affecting the side of onset most, or clinical course of over 10 years, must be present for a definite diagnosis.

Recently it has been established that even at early disease stages, PD is associated with cognitive impairments involving executive functions, working memory, 
impulse control, reversal learning, and decisionmaking, as well as emotional disturbances including depression, apathy, and anxiety causing a generally decreased quality of life [2-9]. These non-motor manifestations of PD are to a great extent considered to result from a deficient dopaminergic innervation of limbic and prefrontal cortical brain regions following disease progression and are thus more pronounced at later disease stages. The syndromes may be further deteriorated by additional degeneration of the cholinergic, noradrenergic, and serotonergic neurotransmitter systems [10-13]. Moreover, the medical and surgical treatments administered to relieve motor symptoms play complex roles via their indirect influence on unaffected brain regions potentially inducing cognitive and emotional dysfunctions. Weintraub and Nirenberg [8], Crossman [14], and Cools et al. [3, 4] recently discussed and presented results supporting the hypothesis that the behavioral syndromes depend on disturbances in the balance between the depleted dorsal striatum and the dominance of the relatively intact ventral striatum (including the nucleus accumbens) in early stages of the disease $[3,4,6]$. Though dopaminergic treatment in early PD relatively successfully recovers the normal function within the dorsal striatum involved in the sensory-motor circuit, the dopaminergic agents may "overdose" the ventral striatum, potentially resulting in affective disturbances and impulse control disorders (ICDs) [2-4].

In the DSM-IV [15], ICDs define a category of behavioral disorders characterized by recurrent maladaptive disinhibited behavior despite personal and relational consequences. Among these are pathological gambling, compulsive buying, hypersexuality, and binge eating. Since the early case report by Seedat et al. in 2000 [16], it has been well documented that dopaminergic medication in a subgroup of PD patients induces ICDs and related compulsive disorders such as hobbyism, punding (i.e. various behavioral stereotypies), and the dopamine dysregulation syndrome (DDS) characterized by addiction-like self-medication of high doses of levodopa and short-acting dopamine agonists [8, 17]. The behavioral complications most often appear, or worsen, after initiation of $D_{2} / D_{3}$ dopamine agonist therapy or dosage increase. In addition, symptoms tend to improve or disappear upon dosage decrease or discontinuation of the dopamine agonist treatment $[8,18-22]$. The various syndromes affect $6-15.5 \%$ of PD patients [21, 23-28] compared to a prevalence of ICDs of $1.1-1.6 \%$ in the general adult population [23, 24, 29, 30]. Moreover, ICDs have been associated with subthalamic nucleus deep brain stimulation (STN DBS) in subgroups of patients [23, 31-42], where the results still present important controversies and disagreements [32, 42-44]. We return to this discussion later.

The etiology and pathogenesis of treatment-induced ICDs in PD remain unknown, though altered activity of the mesolimbic dopamine system has been suggested to be responsible for the phenomenon [23, 45]. Besides a high dose of dopamine agonists, additional risk factors associated with ICDs in PD include young age at PD onset (often in early forties), male gender, a novelty seeking personality, a personal or family history of addictive behaviors, and genetic factors [25, 28, 45-53]. A recent study added depressive symptoms to the list of important risk factors suggesting that the variance in the risk for developing ICDs is more attributable to the presence of depressive symptoms than to the above-mentioned factors [54]. This gained further support through a follow-up study describing 22 PD patients without ICDs at baseline, who at follow-up displayed behavioral symptoms significantly associated with an increase in depressive symptoms [55]. This is very interesting since depression is a major comorbidity in PD affecting 30-45\% of patients, and in fact neuronal loss in the substantia nigra is significantly more pronounced in PD patients with comorbid depression compared to patients without depression [9]. Moreover, findings of improved mood disorder symptoms subsequently to treatment with dopamine agonists such as pramipexole serve additional backup to linking depression and ICDs in PD $[9,56]$. For a further discussion of the epidemiology of ICDs in PD, we refer to a recent review by Weintraub and Nirenberg [8].

Here we present a systematic review of literature published between 2000 and January 2013 reporting ICDs in PD [16, 18-22, 26, 27, 32-39, 41, 42, 45, $48,51,53-55,57-132]$. We consider prevalence rates and discuss distinctive forms of cognitive impairments associated with ICDs in PD. Furthermore, complementing the work of Weintraub and Nirenberg [8], we add a discussion of the functional neuroanatomy and the dopamine-serotonin interactions implicated in ICDs in PD. Finally, we consider perspectives for future research and suggest possible implications for the management of ICDs in PD.

The studies included in this review have been identified through PubMed using the following search words: Parkinson's disease, impulse control disorders, impulsivity, cognition, and decision-making. The initial search strategy, which combined the words Parkinson's disease + impulse control disorders, 
identified 346 articles on January 18th 2013. We ended up including 98 empirical studies in the review among which 64 reports examining both PD patients with and without ICDs are presented in Table 1 below. Inclusion criteria were: Empirical studies examining PD patients who developed ICDs or experienced a worsening of ICD symptoms subsequent to initiation of dopaminergic medication or dosage increase. Exclusion criteria were: Reviews or other theoretical studies; studies focusing exclusively on other neurological diseases than PD such as multiple system atrophy or restless legs syndrome; studies on ICDs in unmedicated PD patients; studies focusing solely on treatment of ICDs in PD. However, we will return to the latter topic in our final discussion. A more extensive overview of all 98 studies is presented in the Supplementary Tables 1 and 2.

\section{SUMMARY AND DISCUSSION OF THE LITERATURE REVIEW}

Based on the 98 reviewed reports, we conclude that ICDs occur relatively frequently in PD secondary to dopaminergic therapy. In total 17,286 PD patients were examined during 2000 and January 2013, and in this material $2,455(14.2 \%)$ displayed prior or current symptoms of ICDs during dopamine replacement therapy. However, evaluating prevalence and characteristics of ICDs in PD, we only considered epidemiological studies suitable for this purpose. We reviewed 29 epidemiological studies describing a total of 14,929 patients with PD, including 1,495 patients with ICDs, which corresponds to a mean overall prevalence of $10 \%$ across different cultures. Pathological gambling and hypersexuality appear to be the most prevalent ICDs reported equally frequent in $518(3.5 \%)$ and $524(3.5 \%)$ of the 14,929 PD patients with ICDs, respectively. Binge eating was observed in 383 patients (2.6\%) and compulsive buying in 374 patients $(2.5 \%)$. Related compulsive conditions such as punding and hobbyism were reported in 549 patients $(3.7 \%)$ and DDS in $53(0.4 \%)$, see Fig. 1. In total 377 patients reported symptoms of more than one ICD $(2.5 \%)$.

The prevalence estimates are based on information available in the epidemiological studies in spite of the fact that not all of them assess all types of ICDs and compulsive disorders. Particularly, information on DDS is often not reported, and some papers lack information on which specific types of ICDs patients experienced. Thus, the true prevalence rates might be somewhat higher, which is in fact what Cilia and van Eimeren [133] summarizes on the basis of the DOMIN-
ION study by Weintraub et al. [26]. Moreover, a very recent study in Finnish PD patients reports frequencies of pathological gambling and hypersexuality amounting to $8.8 \%$ and $22.8 \%$, respectively [54], whereas pathological gambling as deviant from other studies was only prevalent in $0.7 \%$ of Turkish PD patients, since gambling is illegal in Turkey [125]. This suggests that cultural differences might exist. Interestingly though, the prevalence rates in Asian samples were almost similar to prevalences in Western samples. Lim et al. [99] demonstrate that approximately $15 \%$ of PD patients in Malaysia display symptoms of ICDs relative to approximately $14 \%$ reported by Weintraub et al. on the basis of the largest cohort to date of 3,090 North American and Canadian PD patients [26]. Thus, it seems that the overall prevalence of ICDs in Asian and Western PD populations are comparable. Instead it seems that the most noticeable cultural difference is the relatively lower doses of dopamine agonists used in Asian samples compared to Western samples [99]. According to Lim et al. [99], piribedil, which like pramipexole and ropinirole is selective for $D_{2} / D_{3}$ dopamine receptors, is the most available dopamine agonist in Asian countries and this compound has also been associated with ICDs [99]. Nevertheless, in the Malaysian sample where piribedil accounted for approximately two thirds of the dopamine agonist usage, only ropinirole and pramipexole were significantly associated with ICD symptoms [99].

Almost all PD patients with ICDs were treated with dopaminergic medication at the time of examination. The majority received a combination of levodopa and dopamine agonists. The most frequently used direct $\mathrm{D}_{2} / \mathrm{D}_{3}$ dopamine agonists were pramipexole, ropinirole, and pergolide, and generally, the daily dose of dopaminergic medication was higher in patients with ICDs. Based on the epidemiological studies, the mean total levodopa equivalent daily dose (LEDD, levodopa and dopamine agonists) in PD patients with ICDs was $1,030 \mathrm{mg} /$ day compared to a total LEDD in PD patients without ICDs of only $679 \mathrm{mg} / \mathrm{day}$. The mean dopamine agonist LEDD was $243 \mathrm{mg} /$ day in PD patients with ICDs compared to $132 \mathrm{mg} /$ day in PD patients without ICDs. It is important to note, however, that LEDDs are most likely calculated based on different formulas, which complicates a direct comparison of LEDDs across studies [134].

Overall, ICD symptoms predominantly occurred subsequent to treatment initiation or dosage increase, and seemed particularly related to the effects of the $\mathrm{D}_{2} / \mathrm{D}_{3}$ dopamine agonists $[20,22,59,63,65,69$, $71,72,74,84,85,88]$. This tendency is reflected in 


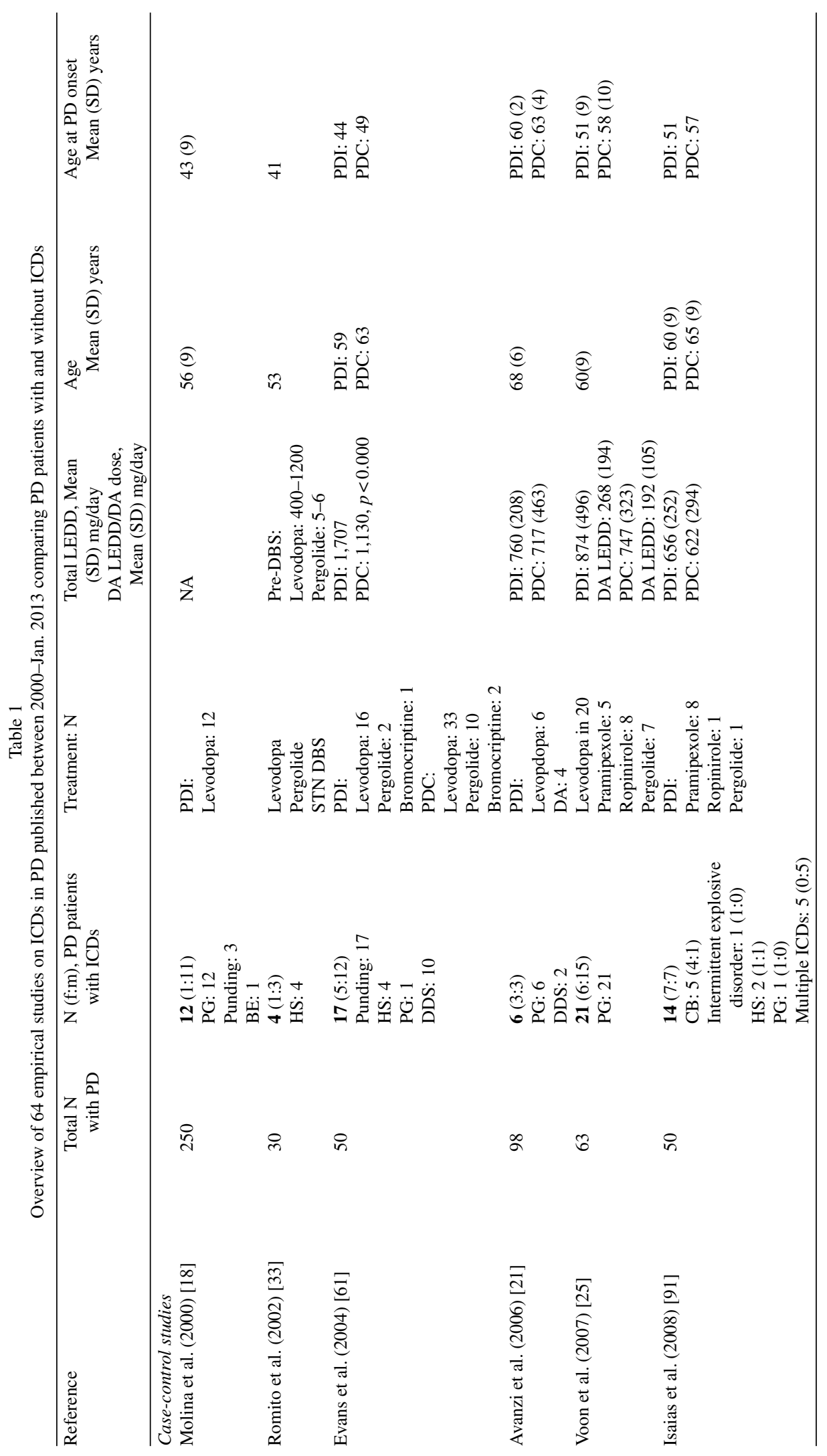




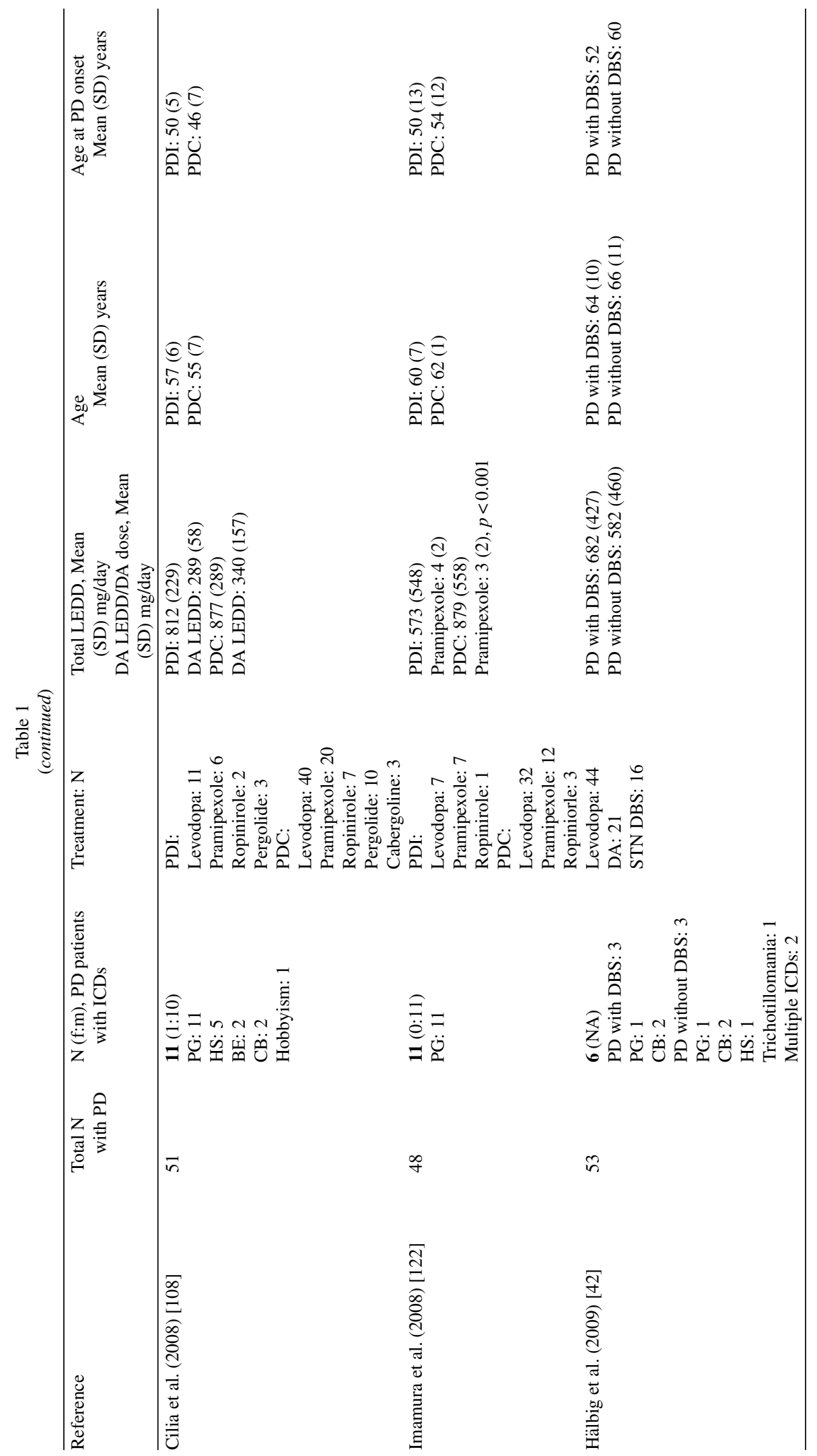




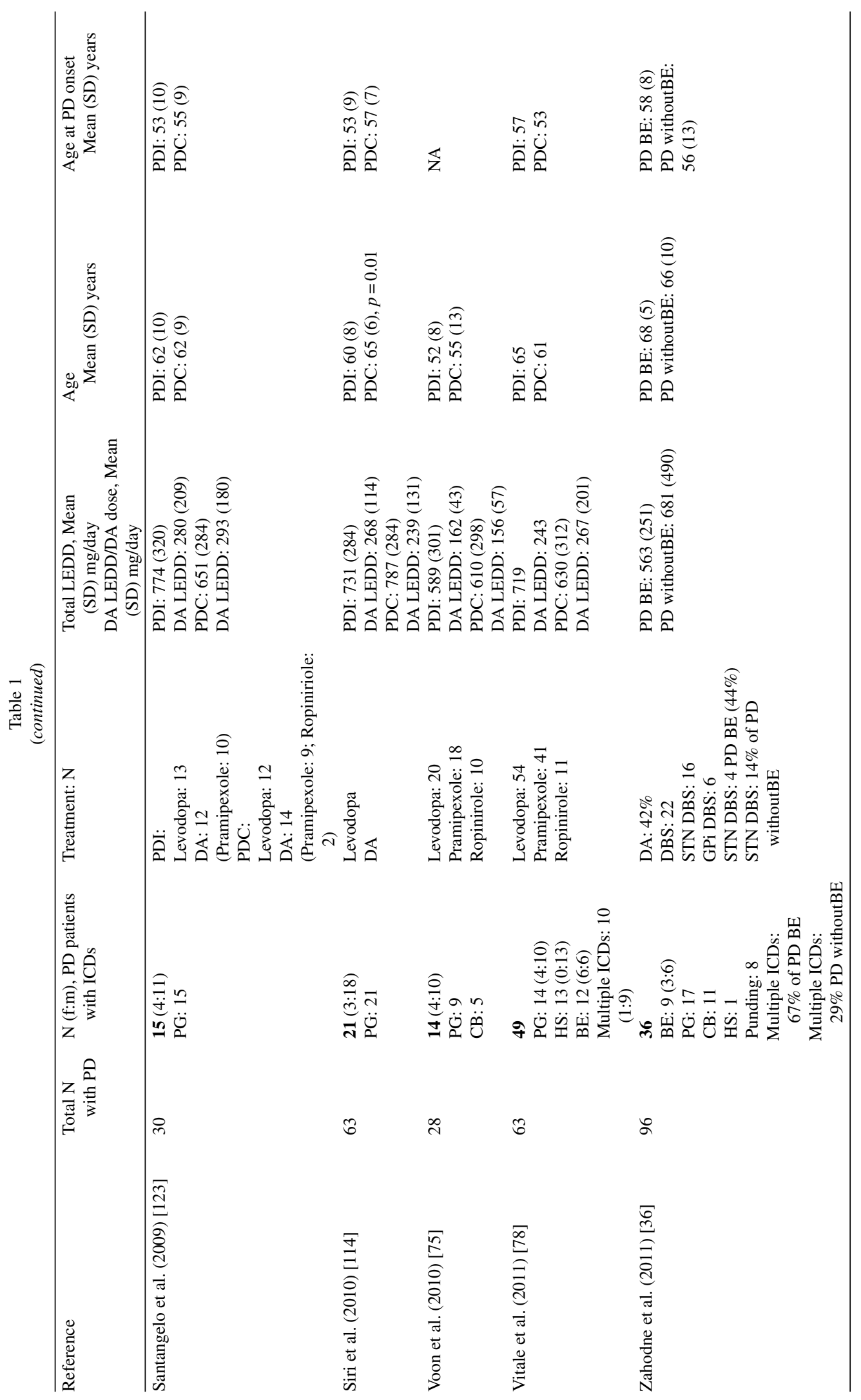




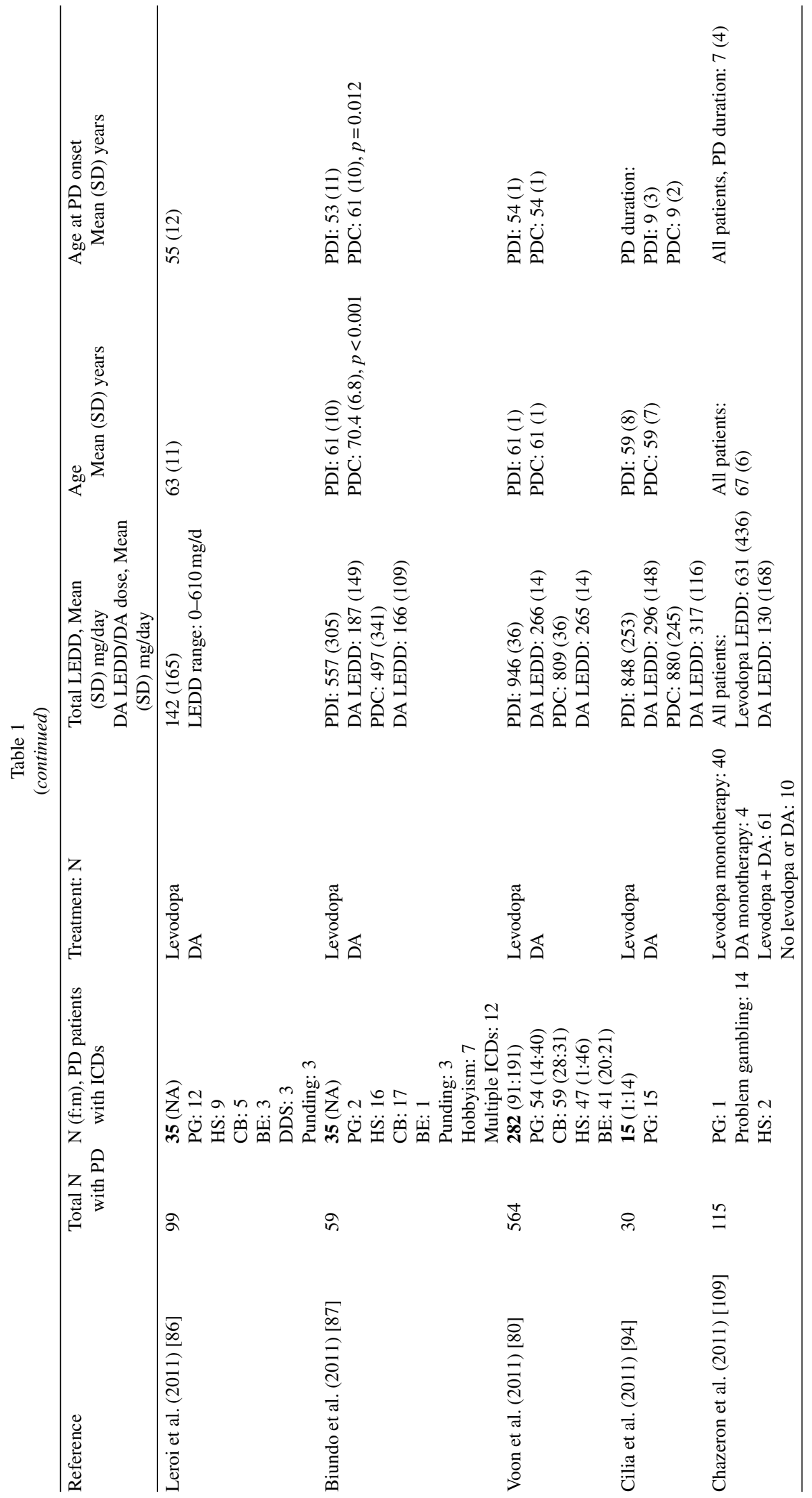




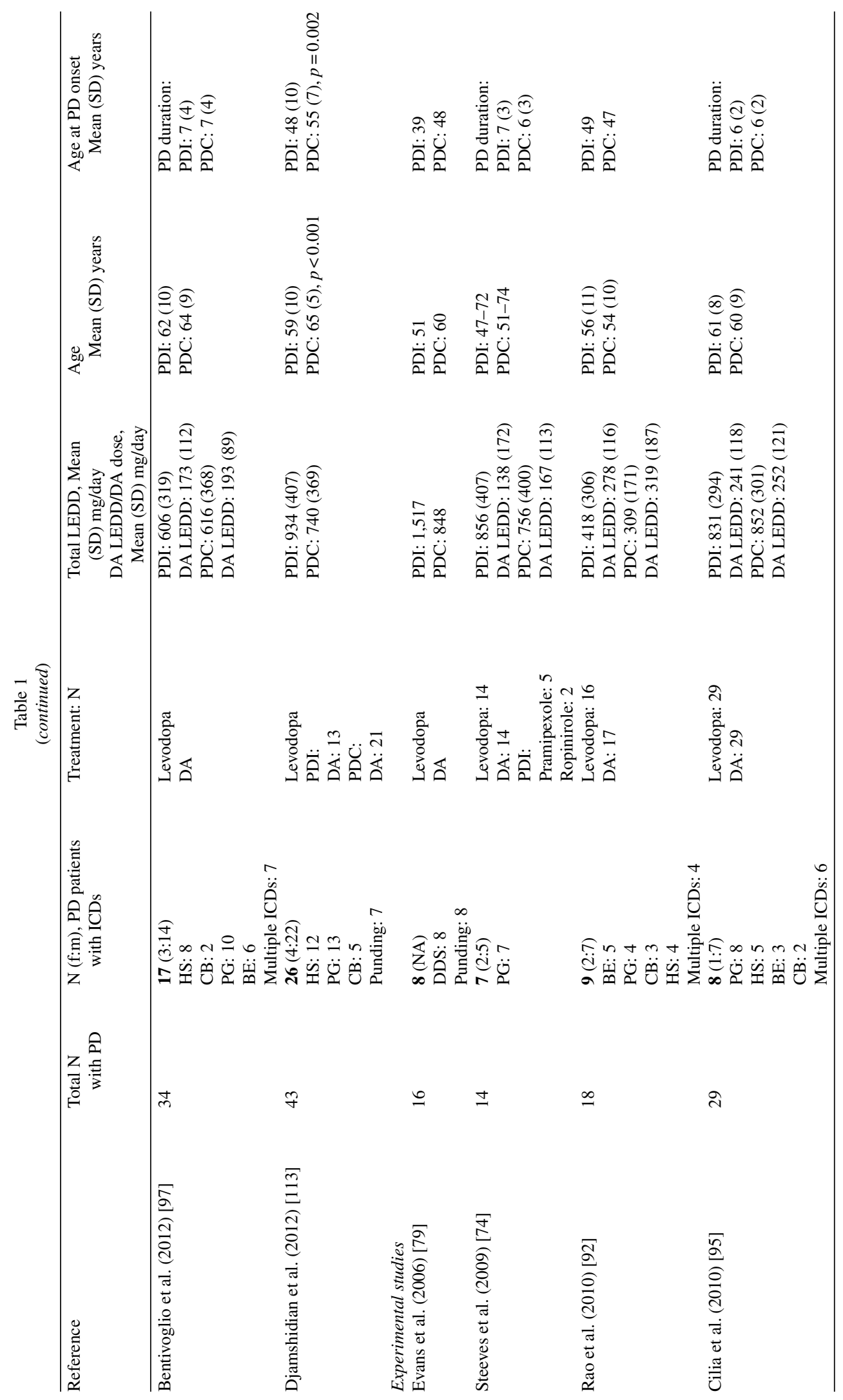


M.B. Callesen et al. / Impulse Control Disorders and Parkinsonism

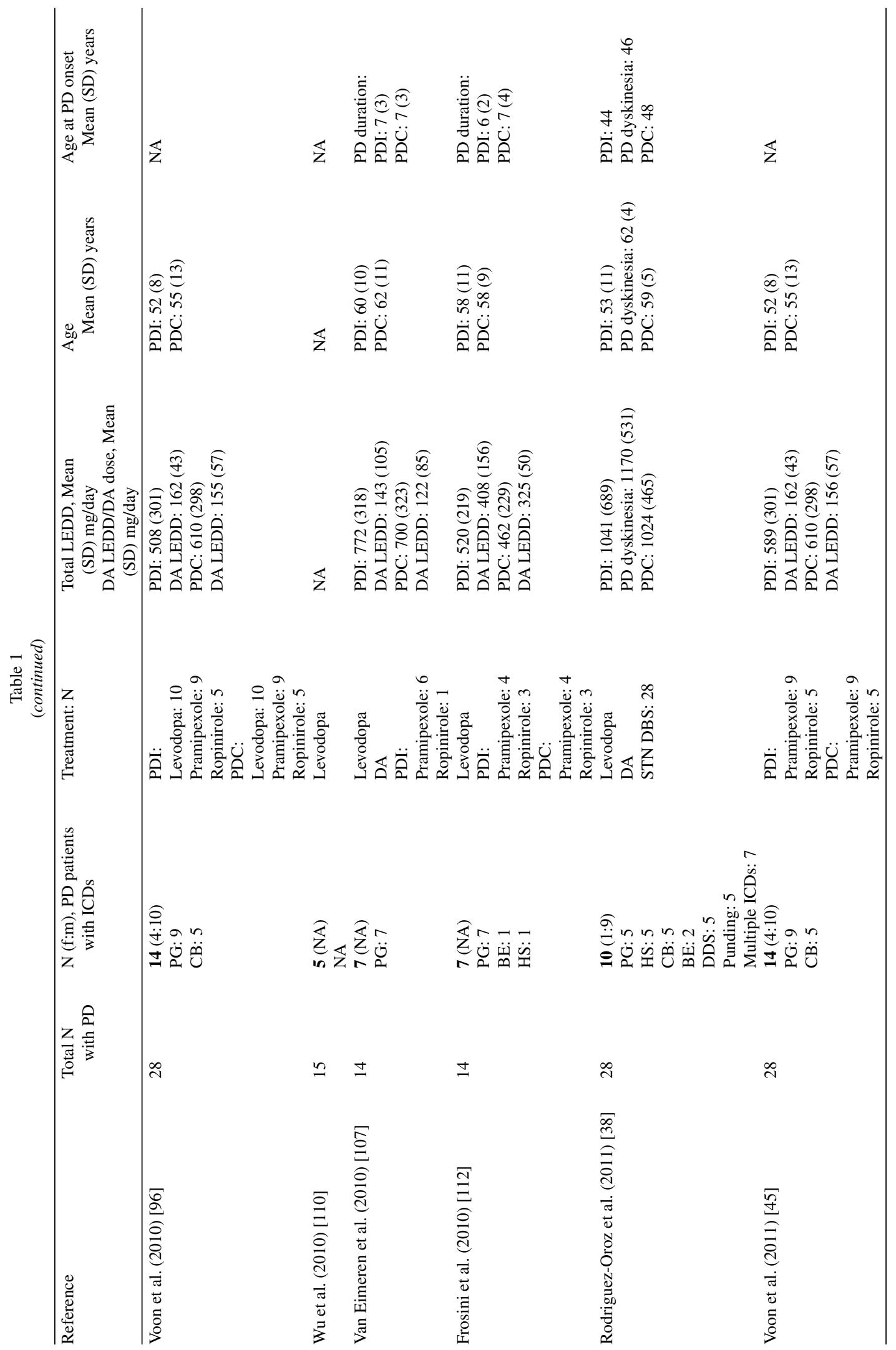




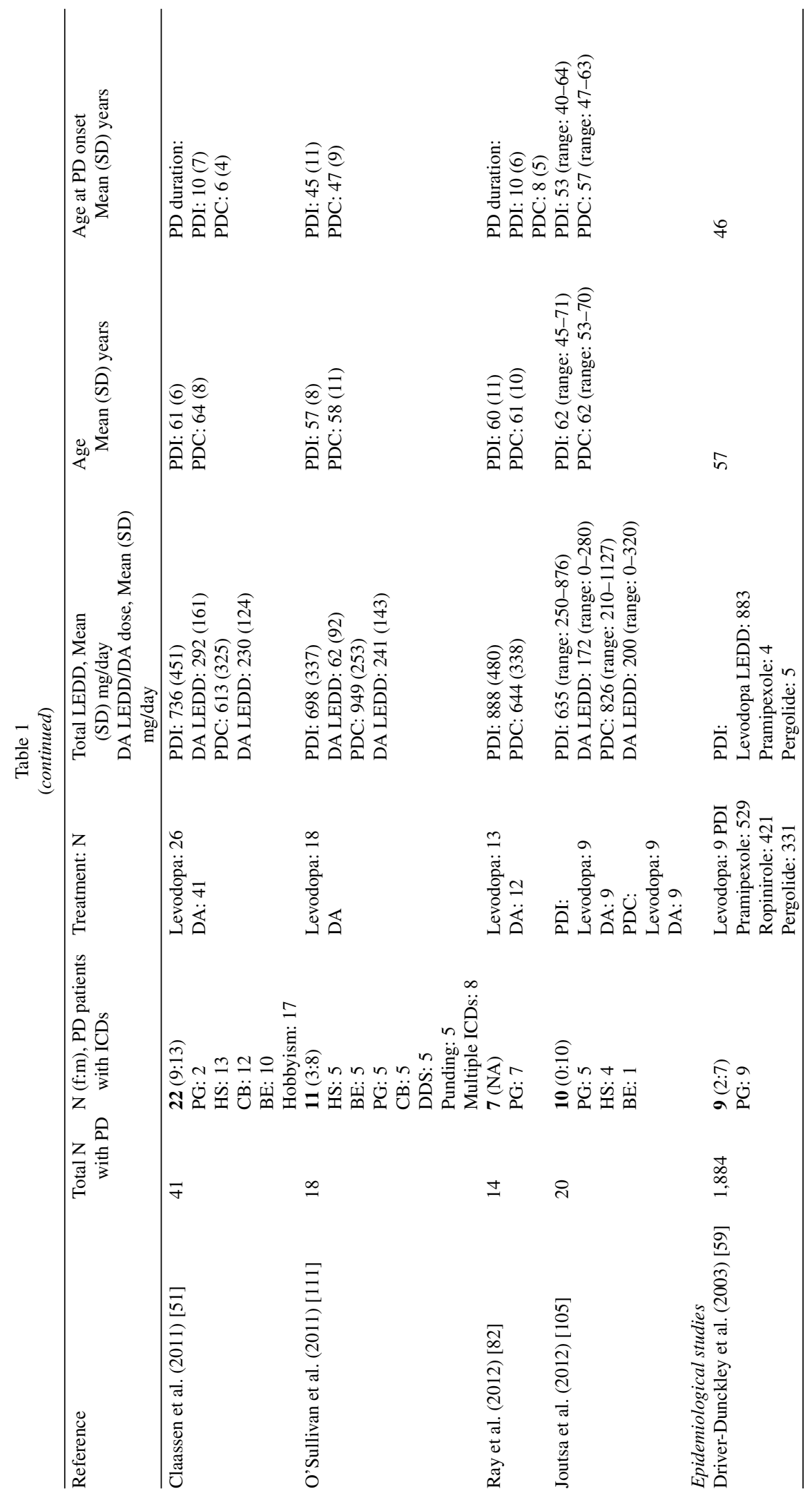




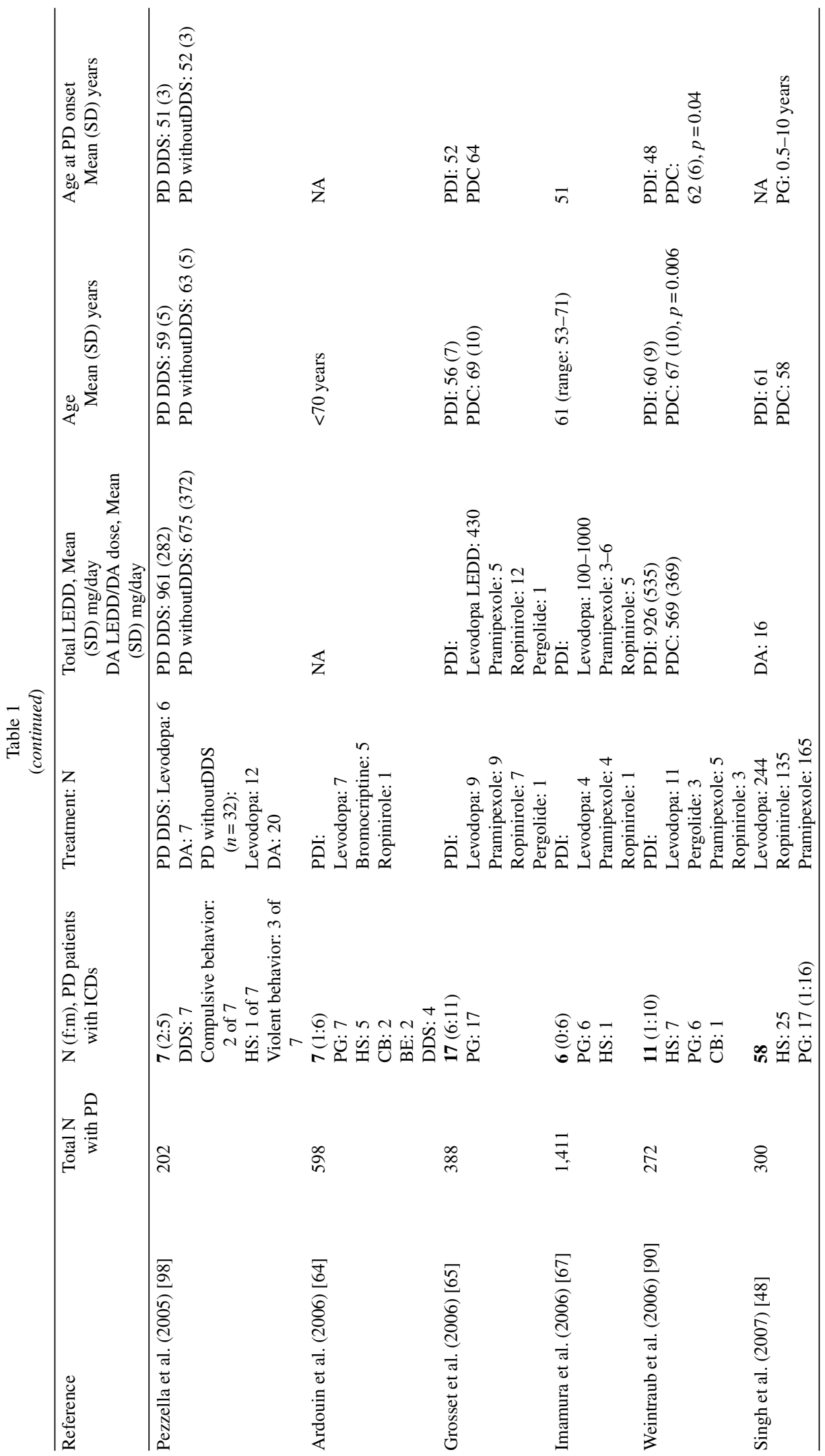




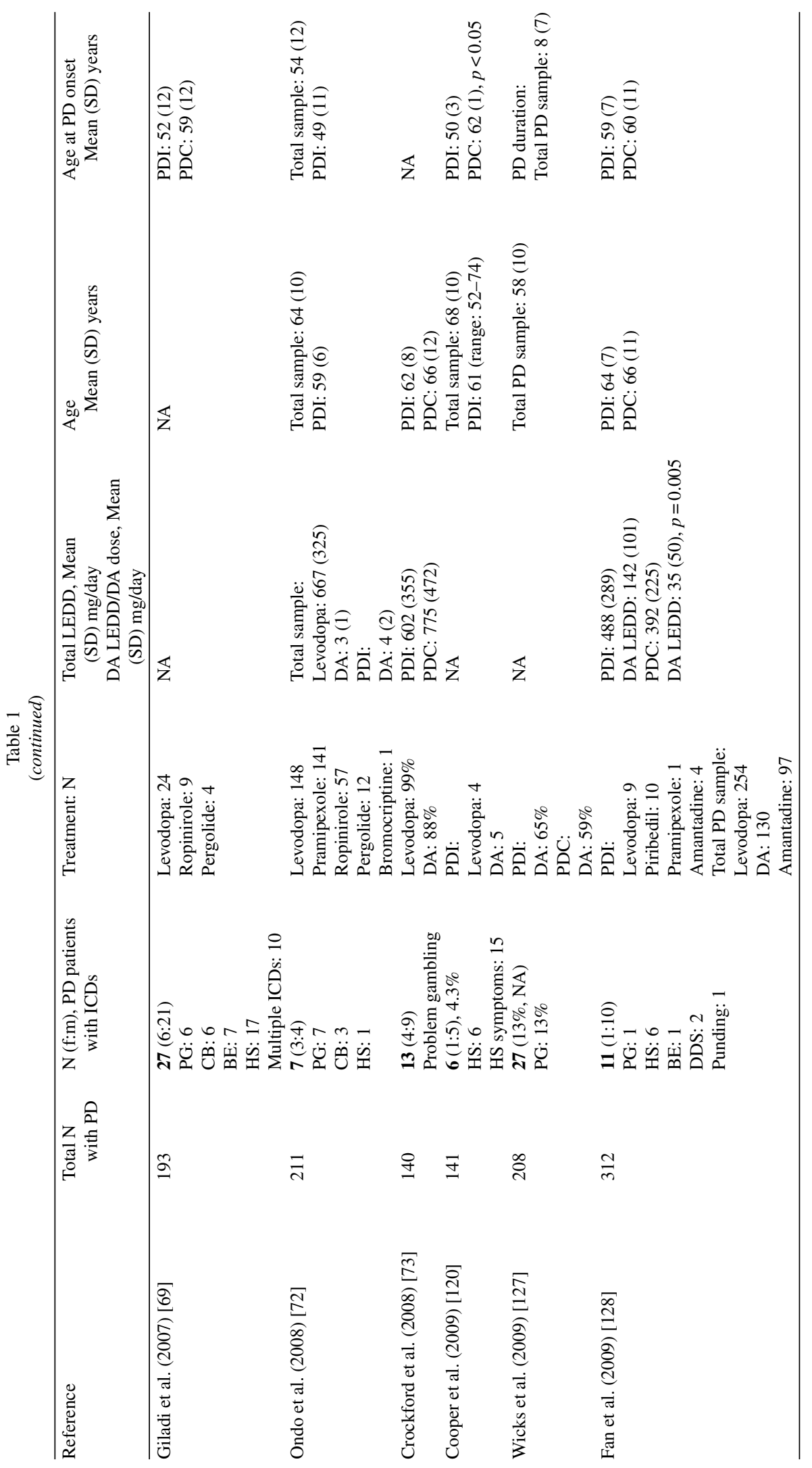




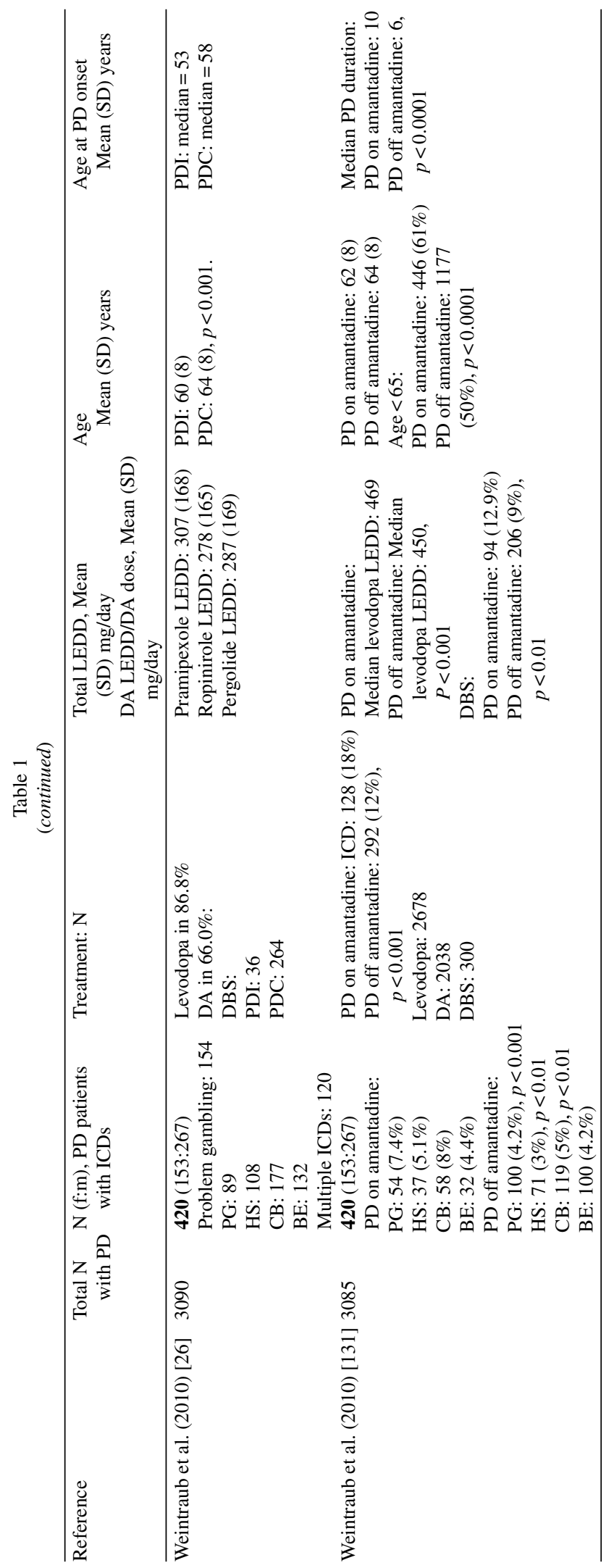




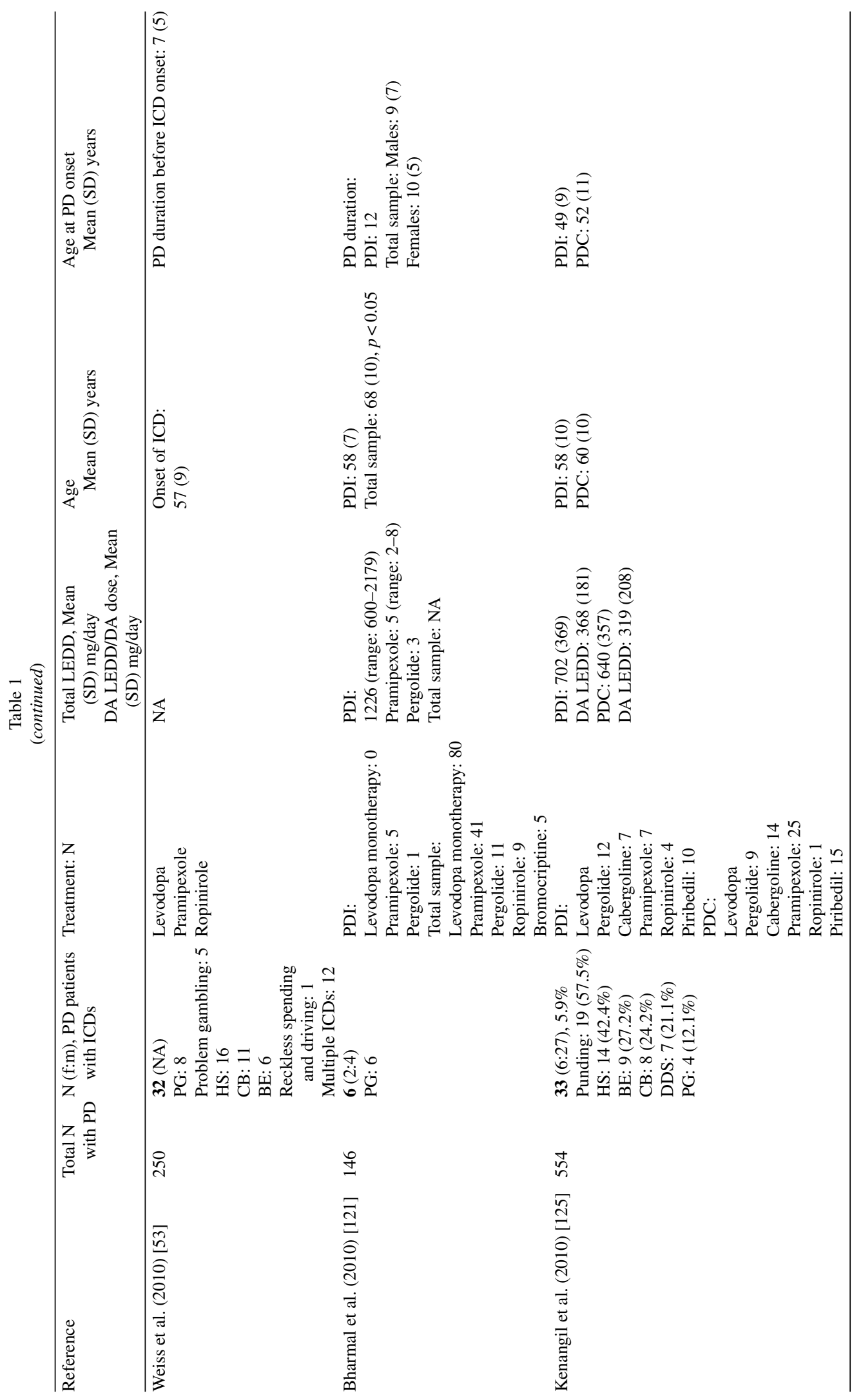




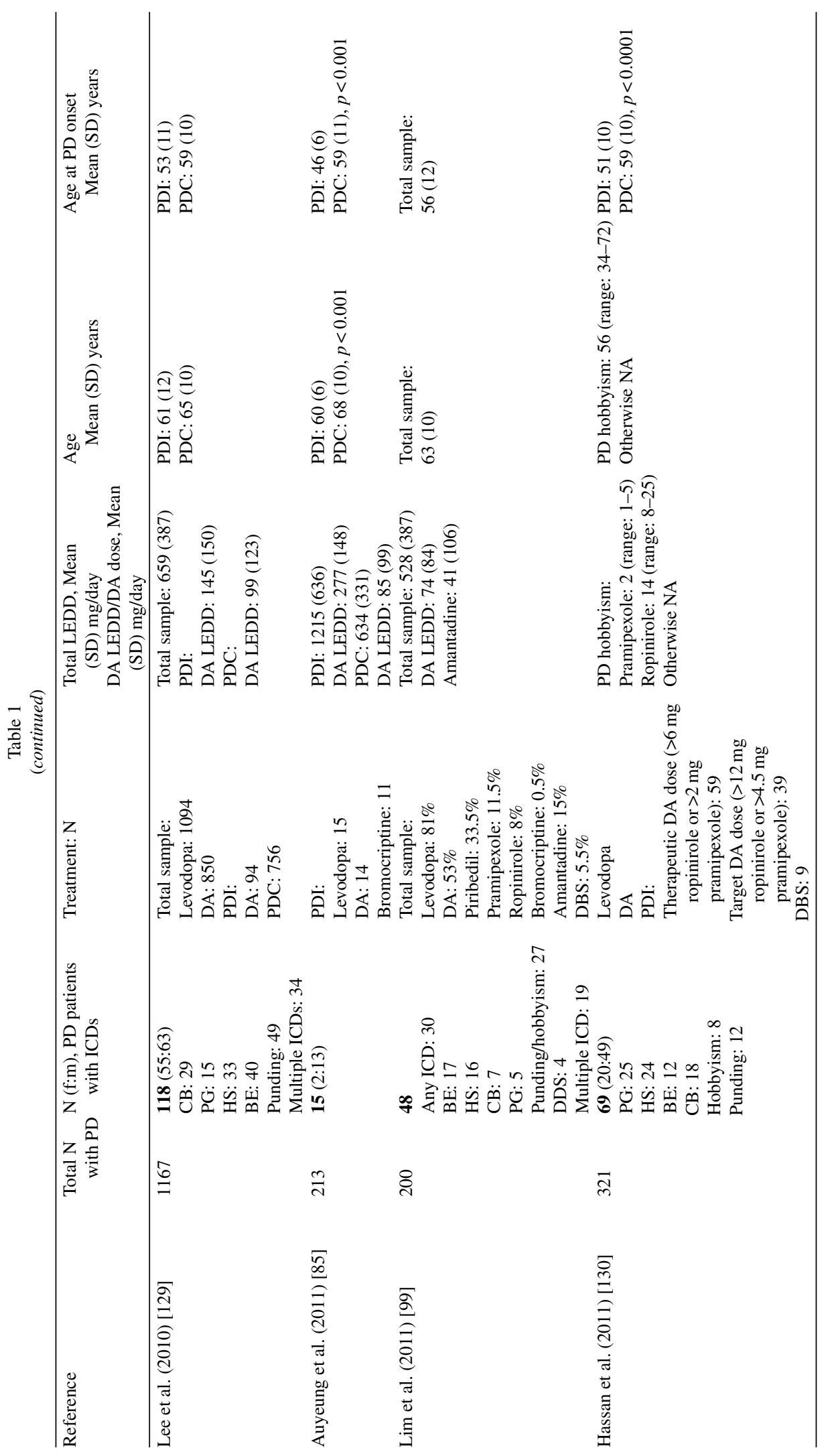




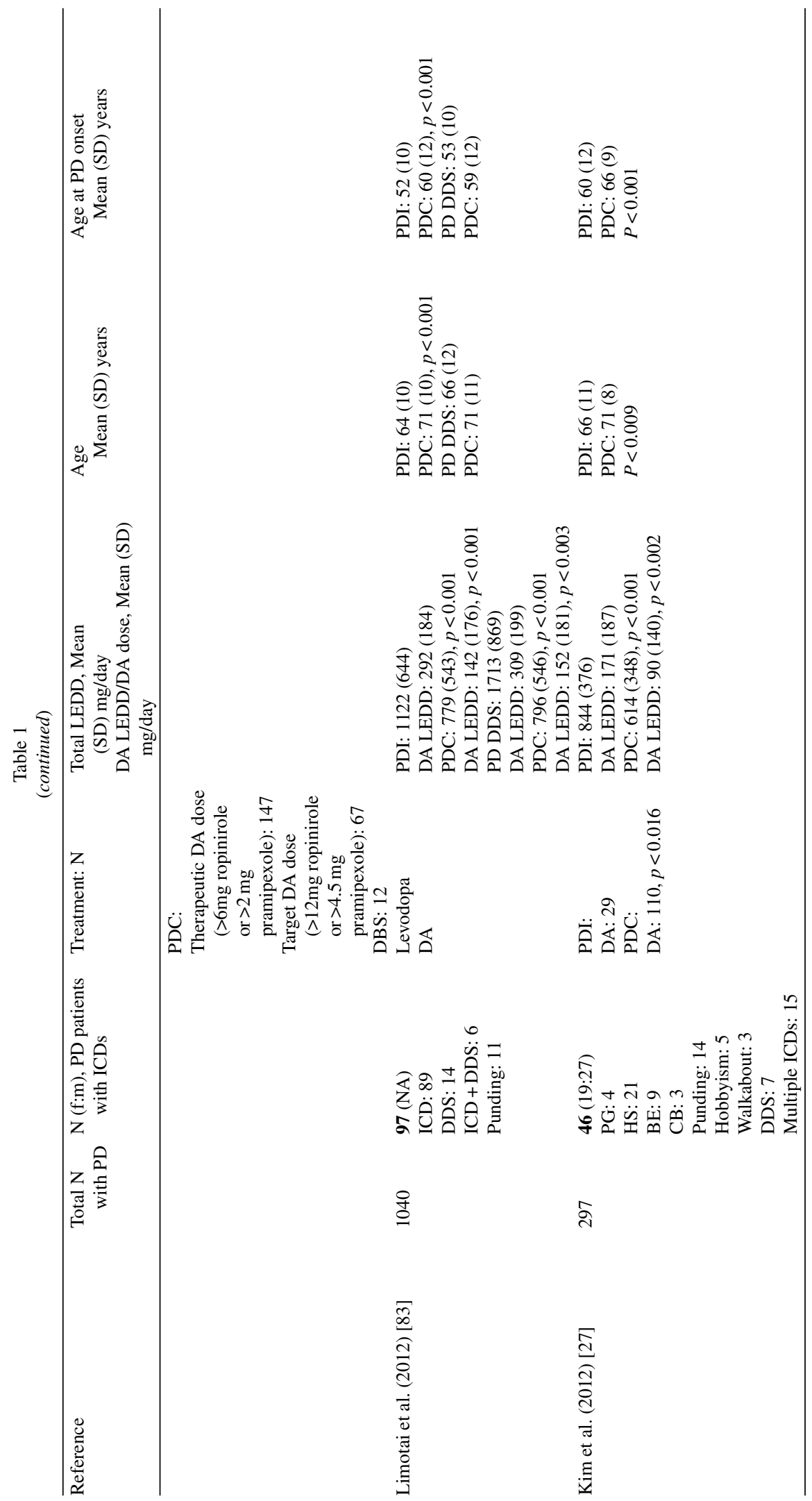




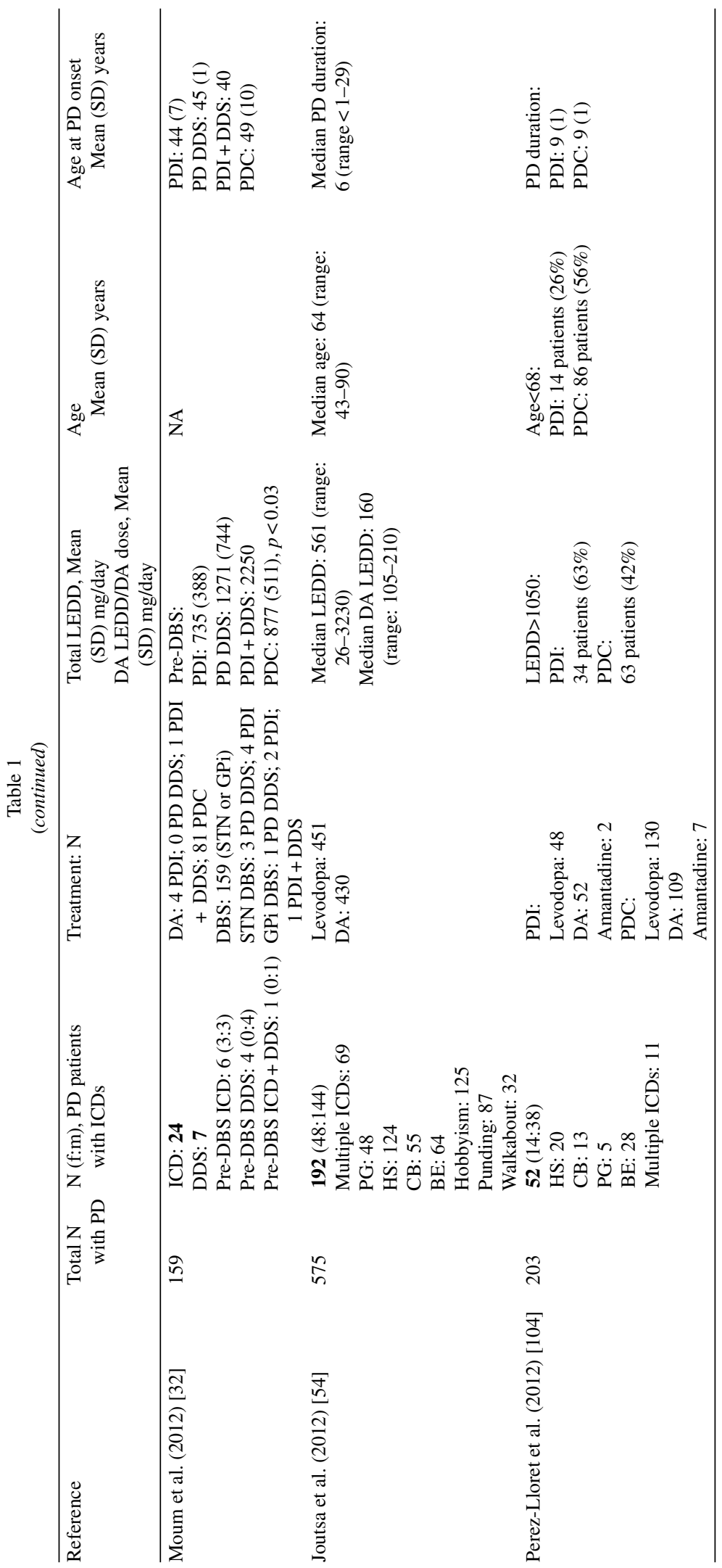




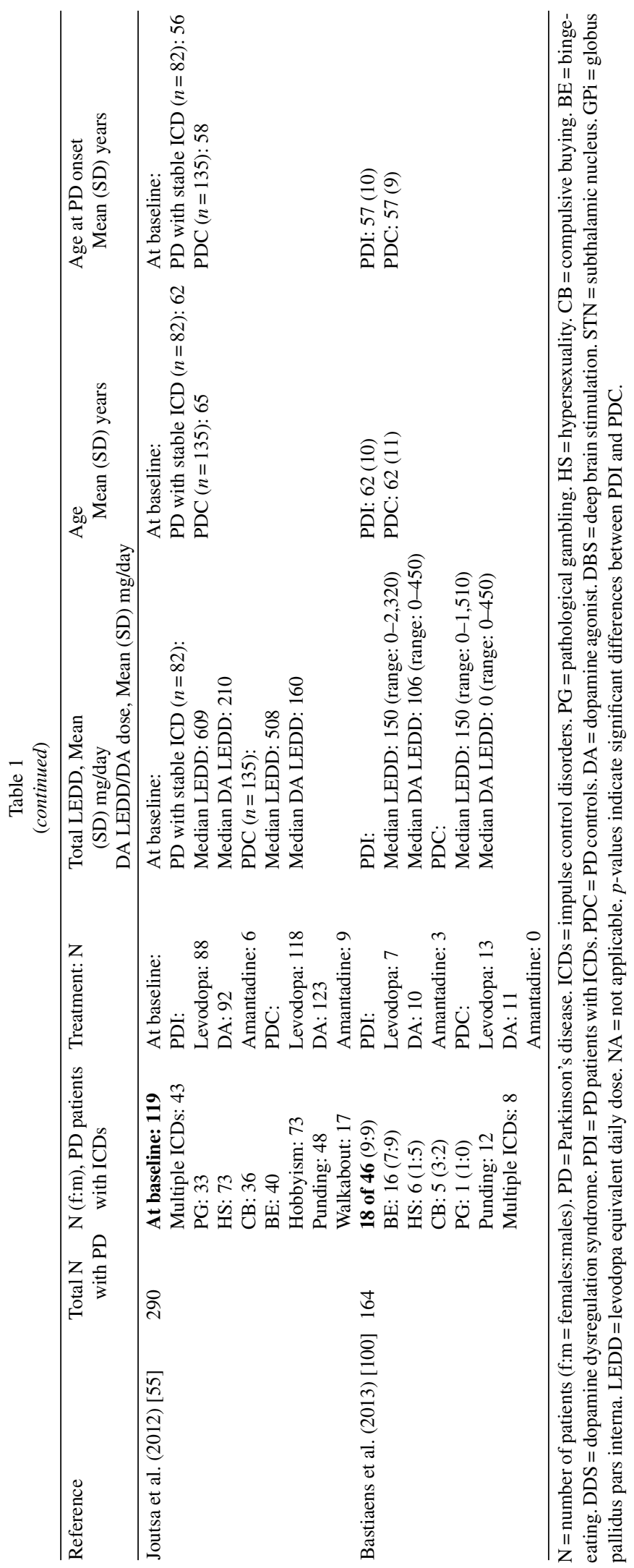




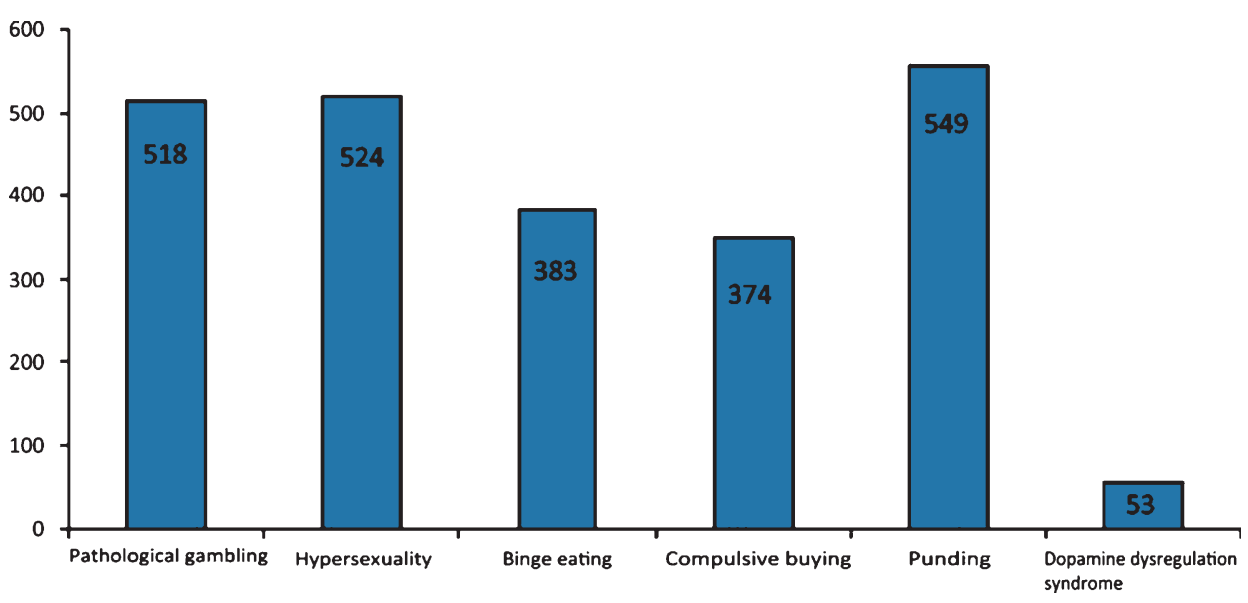

Fig. 1. Illustrates the number of PD patients with ICDs across the specific kinds of ICDs: pathological gambling; hypersexuality; binge eating; compulsive buying; punding; and dopamine dysregulation syndrome. In total 377 patients reported having more than one ICD (2.5\%). Hence, the sum of patients across ICDs $(2,289)$ is larger than the total number of patients $(1,495)$ in the in the epidemiological studies reporting ICDs, since those with multiple ICDs are counted in all respective specific ICDs. Furthermore, the prevalence of DDS is probably underestimated, since information on DDS was unavailable in many of the reviewed report.

a higher frequency of ICDs of up to $17.1 \%$ among PD patients treated with dopamine agonists relative to $6.9 \%$ in patients not treated with dopamine agonists [26]. Generally, ICD symptoms improved or resolved after reduction or discontinuation of dopamine agonist therapy $[18-22,38,48,58,62,66,67,70-72$, $84,88,89$ ], even when increasing levodopa dose as compensation for the lacking agonist treatment [81, 88]. Nevertheless, in most cases described it remains unclear whether ICD onset is a direct result of treatment initiation (or increase) or a consequence of prolonged dopaminergic therapy. Furthermore, most likely individual differences in PD symptomatology, age at disease onset, gender, personality, and psychiatric history influence the treatment-induced ICDs to an unknown degree. In addition, ICDs were already present prior to $\mathrm{PD}$ onset or treatment initiation in at least 28 patients $(1.1 \%)$, a frequency corresponding to the prevalence of ICDs in the general population. These patients reported a worsening of symptoms following medication. Moreover, at least 58 (2.4\%) PD patients with ICDs had a prior history of substance use disorders, while at least $179(7.3 \%)$ and $79(3.2 \%)$ patients with comorbid ICDs reported current or prior symptoms of a mood disorder or anxiety, respectively. Unfortunately, such details of information are simply not available in all included reports. Hopefully, the new screening instruments discussed by Weintraub and Nirenberg [8] may contribute to solving some of these issues in the future.

The presented findings support the concept of treatment-induced ICDs in PD, which we will discuss in a neuro-cognitive perspective taking distinct brain regions, dopamine-serotonin interactions, and cognitive impairments into account.

\section{THE FUNCTIONAL ROLE OF THE SUBTHALAMIC NUCLEUS IN ICDS IN PD}

In the reviewed literature, it has been reported that a minimum of 86 patients with DBS in STN experienced occurrence, worsening, or no improvement of ICD symptoms following surgery [32, 33, 36, 37, 39, $42,93,118]$, which corresponds to $3.5 \%$ of patients with ICDs. In contrast, ICD symptoms declined or were fully alleviated in at least 36 other cases (corresponding to $1.5 \%$ of patients with ICDs) upon DBS in STN, an effect, which is most likely related to the marked reduction in dopaminergic medication following DBS $[32,35,37,38,40,41,64]$. These deviating results strongly suggest that STN DBS influences both motor and non-motor functioning in PD in complex ways via its neuronal network connections. It remains open to speculation whether the discrepancies relate to the coordinates of stimulation or alternatively result from changes of the basal tonus of endogenous or exogenous dopamine in the basal ganglia-cortical loops [135]. One assumption might be that stimulation of the ventromedial STN through its close connection to the nucleus accumbens via the ventral pallido-medial STN neuronal loop potentially induces ICD symptoms, since the ventral striatum, and the nucleus accumbens in particular, is crucial in impulse control, motivational 
processes, and addictive behaviors [38]. Understanding the underlying mechanisms behind these issues is further complicated by different frequencies of stimulations leading to very different outcomes probably influencing both the ventromedial and lateral STN. Contrasting incidences have been reported where STN DBS has not only been linked to increased impulsivity and ICDs [44, 136], but also to lack of motivation and even severe apathy and anhedonia $[9,137]$. According to Tang and Strafella [9] and Volkmann et al. [138], apathy, often co-occurring with depression, is one of the most common adverse effects of STNDBS documented in $24.6 \%$ of PD patients three years after surgery. However, a decrease in apathy severity within 3-6 months after surgery has been observed, indicating that perhaps apathy is only related to medication withdrawal or DBS itself in the immediate postoperative period. This suggests, that apathy could be a consequence of disease progression as well, that might be relieved by dopamine replacement therapy $[9,56,138,139]$. Thus it appears that ICDs and apathy in PD, though representing opposite extremes of a continuum, are somehow related to the same brain structures and networks mediated by dopaminergic therapy [138, 140, 141].

It remains a current hypothesis that DBS applied to the lateral STN region supports sensory-motor loops, whereas DBS applied to the medial STN influences ventral mesolimbic-nucleus accumbens-frontostriatal circuitry. Rodriguez-Oroz et al. [38] demonstrated that PD patients with ICDs and PD patients with severe motor dyskinesia secondary to STN DBS both display theta-alpha $(4-10 \mathrm{~Hz})$ activity, but at different frequencies. PD patients with ICDs thus display activity (mean peak at $6.71 \mathrm{~Hz}$ ) 2-8 $\mathrm{mm}$ below the intercommissural line, whereas PD patients with dyskinesia display theta-alpha activity (mean peak at $8.38 \mathrm{~Hz}$ ) $0-2 \mathrm{~mm}$ below the intercommissural line [38]. In PD patients with ICDs, cortico-subthalamic coherence was most frequent at $4-7.5 \mathrm{~Hz}$ in scalp electrodes placed at frontal regions anterior to the primary motor cortex. This indicates that activity stems from associativeprefrontal and emotional loops involved in cognitive and motivational processes mediated via frontal cortical innervations of the STN. However, it remains uncertain whether the activity upon STN stimulation relates to a reversed STN activation of the cortex or relates to the subcortical loops. In contrast, in PD patients with dyskinesia the cortico-subthalamic coherence was most frequent at $7.5-10 \mathrm{~Hz}$ in electrodes placed over the primary and supplementary motor areas. This suggests that the recorded activity in this group of patients stems from sensory-motor circuits regulating motor control and coordination [38].

It seems obvious that the role of the STN in PD, on both a motor and cognitive level, still needs further investigations. Nevertheless, the STN clearly appears to be situated at an essential position within the basal ganglia playing a central role in not only sensorymotor loops, but also in associative-prefrontal and emotional circuits $[14,31,38]$. A relatively new target for DBS alleviating motor symptoms of PD, which has received increased attention in recent years, is the pedunculopontine nucleus (PPN) [142-144]. The PPN is a tegmental mesopontine nucleus composed of both cholinergic and non-cholinergic neurons with strong reciprocal connections to key output stations of the dorsal and ventral mesolimbic systems of the basal ganglia [142]. The subregions of the PPN are thus involved in the modulation and control of motor performance, attention, procedural learning, reinforcement, and reward processing [142, 145, 146]. Interestingly, deep brain stimulation in PPN, unlike STN DBS, has so far only been associated with the development of ICDs in PD in a single case [118], making it a relevant target for future research.

\section{THE ROLE OF THE NUCLEUS ACCUMBENS AND FRONTAL CORTEX IN ICDS IN PD}

The ventral striatum, and in particular the nucleus accumbens, plays a pivotal role in ICDs and in emotional, cognitive, and addictive processes [147, 148]. It represents a crucial anatomical substrate within the neural networks involving the prefrontal, orbitofrontal, and associative-prefrontal cortical loops, which influence the essential dysfunctional elements present in PD patients with ICDs such as reward evaluation, reversal learning, impulsivity, and temporal discounting [94, $149,150]$. In the following we discuss the impact of these neuronal networks in relation to ICDs in PD based on different neuroimaging techniques.

Using functional magnetic resonance imaging (fMRI), Voon et al. [45] showed a decreased activity within the orbitofrontal cortex and the anterior cingulate cortex during risky decision-making in PD patients with ICDs. They demonstrated an association between dopamine agonists and increased sensitivity towards risk in PD patients with ICDs accompanied by a decreased activity in the ventral striatum. Likewise, Rao et al. [92] observed that PD patients with ICDs had a significantly reduced blood oxygenation level dependent (BOLD) activity in the right ventral 
striatum during risk taking compared to PD patients without ICDs. These results point at a bias towards risky choices in PD patients with ICDs, which might be the behavioral consequence of an impaired risk evaluation following dopamine agonist therapy [45]. In contrast, Voon et al. [96] demonstrated a dopamine agonist-induced increase in ventral striatum activity related to positive prediction error signifying a "better than expected" outcome in PD patients with ICDs potentially resulting in a reward bias. This effect was not seen in PD patients without ICDs. Additionally, PD patients with ICDs had an overall greater orbitofrontal cortex activity to gains and loss omissions and lower activity to losses than PD patients without ICDs [96]. Similarly, Frosini et al. [112] showed an increased BOLD response upon gambling cues bilaterally in the anterior cingulate cortex and in the left ventral striatum in PD patients with pathological gambling compared to PD patients without pathological gambling. In addition, this finding was associated with a cue-induced craving, which resembles that in individuals suffering from addiction [112].

These discrepancies might be explained by differences in the used paradigms. Graef et al. [150], recently showed that while levodopa improved PD patients' performance on an instrumental learning task with constant stimulus-reward contingencies depending on dorsal striato-frontal circuits, treatment impaired performance on a reversal learning task with varying reward contingencies relying on ventral striato-frontal loops. The findings by Graef et al. [150] support the "overdose hypothesis" assuming harmful effects of dopaminergic medication on reward evaluation and other cognitive functions depending on less affected brain regions in PD, such as the ventral striatum, and in particular the nucleus accumbens, in early disease stages [2-4, 150]. This hypothesis is further supported by van Eimeren et al.s [107] positron emission tomography (PET) findings of increased activity in the lateral orbitofrontal cortex, the rostral cingulate zone, the amygdala, and the external pallidum upon apomorphine intake in PD patients without pathological gambling while performing a probabilistic card game. In contrast, PD patients with pathological gambling showed the opposite reaction of apomorphine-induced deactivation of these brain regions resulting in impaired impulse control and response inhibition [107]. Moreover, using singlephoton emission computed tomography (SPECT), Cilia et al. [108] reported hyperactivity during rest in the orbitofrontal cortex, the hippocampus, the amygdala, the insula, and the ventral pallidum in PD patients with ICDs. They argued, that the abnormal resting state in the mesocorticolimbic circuit in this subgroup of patients provided additional support to the "overdose hypothesis" by suggesting a medication-induced overstimulation of the relatively intact reward-related neuronal networks [108].

Functional PET studies of addiction and pathological gambling, have shown an abnormally enhanced phasic dopamine release in the ventral striatum in addicted individuals when confronted with cues of their addiction [20,61, 62, 147, 151-155]. A similar dysfunctional dopaminergic response upon gambling has been shown in PD patients with comorbid pathological gambling [74]. Steeves and colleagues [74], reported a lower baseline binding potential for the dopamine $\mathrm{D}_{2} / \mathrm{D}_{3}$ radioligand $\left[{ }^{11} \mathrm{C}\right]$-raclopride in the ventral striatum of PD patients with pathological gambling compared to PD patients without pathological gambling and a relatively greater decrease in $\left[{ }^{11} \mathrm{C}\right]$-raclopride binding during gambling. This finding may suggest a relatively higher endogenous ventral striatal dopamine release upon gambling in PD patients with pathological gambling than in the PD control group. Similar findings of decreased $\left[{ }^{11} \mathrm{C}\right]$-raclopride binding in the ventral striatum and the caudate nucleus when exposed to rewarding versus neutral visual stimuli were reported by the team of O'Sullivan and Wu in PD patients with ICDs compared to PD controls $[110,111]$ indicating an enhanced endogenous dopamine release. In a SPECT study using the radiotracer FP-CIT, Cilia et al. [95] showed that PD patients with pathological gambling had a lower tracer binding in the ventral striatum compared to PD patients without gambling problems. According to Cilia et al. [95], these results might reflect either a reduction of mesolimbic projections, or a lower dopamine transporter density combined with increased synaptic dopamine levels as previously suggested [74, 108].

The findings in PD patients with ICDs translate to findings in both human and animal studies of addiction suggesting low baseline dopamine receptor availability to be associated with vulnerability of addiction [156-158]. Interestingly, low striatal dopamine receptor availability has also recently been demonstrated in individuals suffering from morbid obesity due to binge eating $[159,160]$. Following this line of arguments, individuals with ICDs and other types of addictions, are likely to seek more potential rewarding events, e.g. the possible gains related to gambling, in order to compensate for a reward deficiency syndrome characterized by a chronic dopamine craving [74, 161]. However, Joutsa et al. [162] very recently argued that a striatal dopamine release during gambling irrespective of out- 
come in fact challenges this hypothesis, which predicts blunted mesolimbic dopamine responses to gambling in pathological gamblers. Thus according to this argument, the findings by Voon et al. [45] and Rao et al. [92] support the reward deficiency hypothesis, whereas the findings by Voon et al. [96], Frosini et al. [112] and Steeves et al. [74] contradict the hypothesis. The expectation of receiving a reward seems to be enough to induce a striatal dopamine release in PD patients with pathological gambling, which is also seen in pathological gamblers without PD [151, 152, 162]. Moreover, the experience of wanting or craving induced merely by visual gambling cues or following loss might serve as another hypothesis for explaining the observed striatal dopamine release [112].

The processing of reward involves aspects of motivation, prediction, and pleasure, also referred to as the psychological components of "wanting", "learning", and "liking" [163, 164]. In addictive behaviors, wanting to a great extent equals craving. Recent studies have shown that even though individuals suffering from addiction do potentially get a dopaminergic enhancement from engaging in the addictive behavior, they might not feel any hedonic impact from the reward of the action. Exactly this is seen in a group of PD patients with DDS [79]. Using PET imaging, Evans et al. [79] demonstrated an increased dopamine release in the ventral striatum upon levodopa intake in PD patients with DDS, which correlated with the patients' subjective feelings of drug wanting (craving) but not liking [79]. This finding hints at liking and wanting components involving different neurotransmitter systems, where wanting seems closely related to the dopaminergic system, and liking seems associated with the opiate system [164]. In fact, the ability to learn to seek reward remains intact in rats lacking up to $99 \%$ of dopamine in the nucleus accumbens, they merely lack the motivation to use the skills they have learned [164]. Thus, consistent with the findings by Graef et al. [150], one could argue that the reward system is not only a dopamine-driven system rather it includes a combination of a dopaminergic motivational part and an opioid dependent pleasure part.

In summary, the nucleus accumbens certainly seems to play a key role during the acquisition phase of addictive behaviors, whereas the dorsal striatum is particularly important in maintaining an addiction [147, 150, 165]. This transition seems to be facilitated by the direct $\mathrm{D}_{2} / \mathrm{D}_{3}$ dopamine agonists on hypersensitive postsynaptic dorsal striatal dopamine receptors. Anatomically, the shift from initiation to consolidation of an addiction might reflect an equivalent shift from limbic to associative-prefrontal and sensory-motor circuits via the ventral tegmental area and the substantia nigra zona compacta dopaminergic ascending loops innervating the dorsal striatum [150, 165, 166]. The discussed findings highlight the importance of the orbitofrontal cortex, the anterior cingulate cortex, and the ventral striatum in risk evaluation, which is mediated by dopamine agonists in ICDs in PD. Thus, these findings might explain why dopamine agonists are important risk factors for developing ICDs in PD [45, 51, 167]. Furthermore, several studies show an altered dopaminergic activity within the ventral striatum in PD patients with concomitant ICDs resembling the dopaminergic activity observed in non-PD individuals suffering from other kinds of addiction. However, these issues are still not sufficiently investigated, and research suggests that dopamine and dopaminergic therapy are not the only agents that may impact the course of the disease. Other neurotransmitters are depleted in PD as well, and in the following we discuss the influence of serotonin in ICDs in PD.

\section{THE ROLE OF SEROTONIN IN IMPULSE CONTROL DISORDERS IN PARKINSON'S DISEASE}

It is obvious that dopamine agonists are not able to fully compensate for the natural physiological tonic/phasic release of dopamine or the inactivation by the re-uptake transporter following its release, since the dopaminergic nerve terminals are degenerated in PD. Among other important neurotransmitters depleted in PD is serotonin, whose impact on nonmotor manifestations of the disease is still subject to much debate [9-12]. Furthermore, the possible role of a decrease in serotonergic activity in PD patients with ICDs with regard to impulsivity, response inhibition, and temporal discounting remains to be established. The serotonin innervations originating from the dorsal raphe nucleus supplies approximately $80 \%$ of the serotonergic innervation to the prefrontal and motor cortices as well as to the subcortical structures involved in PD (striatum, pallidum, STN, substantia nigra, and PPN) [168]. In PD, the role of serotonin is very important in relation to both ICDs and emotional disturbances associated with the disease, such as depression, apathy, and anxiety [10]. It is beyond the scope of this review to discuss the complex details regarding the interactions between dopamine and serotonin, since this topic has already been covered by excellent reviews [169-171]. Consequently, only a few 
highlights from the published literature will be discussed.

In conjunction with dopamine, serotonin seems to play an essential role in the modulation of impulse control, risk taking, and decision-making, and the activity of serotonin has been associated with enhanced reversal learning and attentional shifting, increased response inhibition, and decreased delay discounting [158, 170, 172-176]. Moreover, Campbell-Meiklejohn et al. [177] recently found that serotonin and dopamine complement each other in loss chasing (i.e. gambling to recover losses) in pathological gamblers. While serotonin activity seems related to persistent loss chasing, dopamine activity appears to regulate the magnitude of the losses being chased [177]. In addition, Long et al. [178] demonstrated that serotonin depletion shapes risky decision-making in macaque monkeys trained to perform a simple gambling task for rewards. Reducing serotonin synthesis resulted in a decreased preference for more conservative options in the gambling task, resulting in riskier decision-making in the monkeys. These findings introduce an important issue concerning the balance between high and low levels of serotonin leading to different, sometimes almost opposite, neural network activations and behavioral outcomes. Macoveanu et al. [175] recently demonstrated that high and low levels of serotonin had opposite effects on activity in the dorsomedial prefrontal cortex and the amygdala related to negative outcomes following low-risk decisions in a gambling task. In the dorsomedial prefrontal cortex, low levels of serotonin increased the negative outcome-related neural activity, whereas high levels of serotonin resulted in a decreased activity [175]. The opposite neural reaction to negative outcomes in the gambling task was present in the left amygdala, where high levels of serotonin led to increased activity relative to a decreased activity associated with low levels of serotonin [175].

The balance between high and low levels of serotonin is furthermore implicated in impulsivity. Miyazaki et al. [176] demonstrated the importance of serotonin in temporal discounting through findings of increased serotonergic firing facilitating waiting behavior towards future rewards. These results suggest that in addition to the implications of dopamine depletion, low levels of serotonin, e.g. as a result of serotonergic degeneration in $\mathrm{PD}$, might be essential in explaining the inability in PD patients with ICDs to wait for a reward and hence contributing to their maladaptive behavior.

To summarize, the presented results suggest that both the dopaminergic and the serotonergic systems are implicated in temporal discounting and risk-sensitive decision-making in general as well as in pathological gambling and other ICDs. Furthermore, the findings cautiously hint at potential dose-dependent pharmacological therapies for ICDs and addiction. Consistent with preclinical findings, a case study demonstrated a positive treatment response in a patient administered fluvoxamine to treat pathological gambling [179]. Whether similar selective serotonin reuptake inhibitors, or perhaps direct serotonergic agonists aiming at specific receptor subtypes, might ameliorate pathological gambling and other ICDs in early PD, perhaps at least in patients with comorbid depression, remains an open question for future research to address $[49,180]$. In addition, it appears highly clinically relevant to further investigate how ICDs in PD impact the patients' daily functioning. In the following, we discuss cognitive impairments associated with ICDs in PD.

\section{COGNITIVE SYMPTOMATOLOGY IN IMPULSE CONTROL DISORDERS IN PARKINSON'S DISEASE}

Cognitive processes such as attention, planning, and anticipation are of ultimate importance in social interaction, learning, and decision-making [3, 4, 6, 181, 182]. It is well known that PD patients without ICDs experience cognitive difficulties in domains related to the fronto-striatal loops as their disease progresses [11-13, 28, 183, 184]. According to Hirano et al. [13], the mesocortical dopamine system affected in PD is associated with executive functions and is mediated via levodopa medication and dopamine metabolism. Cholinergic impairment in PD is also implicated in attention and working memory and the role of acetylcholine in development of dementia is supported by acetylcholinesterase PET imaging [13]. Furthermore, research indicates that despite relatively preserved functions of the orbital and ventromedial prefrontal cortex in early disease stages, cognitive impairments might even occur in early PD, though most likely as a consequence of dopaminergic treatment $[185,186]$. Below, we discuss findings based on a selection of cognitive tasks dependent on frontal cortical functions comparing PD patients with and without ICDs.

\section{Executive functioning}

The Stroop test and the Wisconsin Card Sorting Test represent two widely used tasks to evaluate executive functions. The Stroop test, which measures selective 
attention, cognitive flexibility, and speed of cognitive processing, has been associated with activation in the anterior cingulate cortex and the dorsolateral prefrontal cortex [187]. Similarly, the Wisconsin Card Sorting Test is a test of set shifting measuring cognitive flexibility. This test has been associated with activation of the dorsolateral prefrontal cortex as well as the ventrolateral prefrontal cortex and the caudate nucleus, which also modulate working memory functions [188-190]. Various studies have shown that PD patients perform poorly on both of these tests revealing a deficit in alteration or maintenance of a learned strategy based on task-dependent feedback and impaired impulse control regulation [183, 184, 191-195]. However, findings of preserved executive functions in PD exist as well, at least in early PD [196].

In PD patients with concurrent ICDs, Vitale et al. [78] recently demonstrated deficits on executive tasks exploring cognitive flexibility and spatial planning. In addition, they noticed that the cognitive difficulties associated with ICDs in PD differed depending on the specific kind of ICD patients presented. PD patients with hypersexuality and multiple ICDs performed worse on verbal learning and memory tests compared to PD patients with pathological gambling [78]. Particularly, the PD patients with comorbid hypersexuality revealed more general cognitive deficits, poorer inhibitory control, and reduced immediate and delayed memory compared to PD patients with pathological gambling [78]. These findings suggest that hypersexuality in PD is associated with a more profound deficiency in the balance of the associative-prefrontal and emotional-limbic circuits than pathological gambling in PD. Additionally, compared to PD patients without pathological gambling, Santangelo et al. [123] reported impaired performance in PD patients with pathological gambling on cognitive tasks evaluating long-term memory and frontal lobe functions, including the Frontal Assessment Battery, phonological fluency, and the Trail Making Test. In contrast, Siri et al. [114] demonstrated preserved executive functions in PD patients with pathological gambling. Compared to PD patients without pathological gambling, patients with gambling problems revealed higher general cognitive abilities and performed better on attention and verbal fluency [114].

\section{Reversal and reinforcement learning}

Closely related to cognitive flexibility is reinforcement and reversal learning, which has also been found to be compromised in PD, at least in medicated patients
[186, 197]. Reversal learning impairments appear to be particularly pronounced following treatment with the dopamine $\mathrm{D}_{2} / \mathrm{D}_{3}$ receptor agonist pramipexole [3, 198, 199]. In line with our previous discussion of the functional neuroanatomy of ICDs in PD, the results on cognitive impairments in PD might be explained by a treatment-induced disruption of functional activity within the nucleus accumbens, which is involved in alteration of behavioral strategy. Interestingly, Cools et al. [148] demonstrated that reversal learning was in fact accompanied by increased nucleus accumbens activity only in medicated PD patients. Current neuroanatomical studies strongly suggest that the modulatory influence on cognition via the nucleus accumbens appears to be mediated by its upstream neuronal looping through the ventral pallidum and thalamic projections to the frontal cortex [166, 200]. Furthermore, the aforementioned fMRI study by Voon et al. [96] demonstrated that dopamine agonists increase the rate of learning from gain and enhanced ventral striatal activity to positive prediction error in PD patients with ICDs, an effect that was not present in PD patients without ICDs. In contrast, dopamine agonists induced a decrease in learning from loss in PD patients without ICDs but not in PD patients with ICDs [96]. Lastly, PD patients with ICDs had greater orbitofrontal cortex activation upon gains relative to lower activation upon losses compared to PD patients without ICDs both on and off medication [96]. However as previously discussed, Graef et al. [150] showed that dopaminergic treatment affects tasks implicating diverse neuronal networks differently.

\section{Decision-making under ambiguity}

A wide range of cognitive tasks is designed to examine decision-making. Among these are the Iowa Gambling Task, the Cambridge Gambling Task, the Game of Dice Task, the Balloon Analogue Risk Task, and the Beads Task, which are all associated with the limbic-orbitofrontal-striatal loop [201]. The Iowa Gambling Task is most often used to measure decisionmaking under ambiguous scenarios with implicit rules and it is known that patients with deficits in the orbitofrontal and ventromedial prefrontal cortex and the amygdala perform poorly on this task [201-203]. Also, PD patients have revealed impaired performance on the Iowa Gambling Task [97, 194, 196, 204-208] and this has even been found in early disease stages despite preserved executive functions [196]. In contrast, Euteneuer et al. [201] observed intact Iowa Gambling Task performance in PD patients without 
ICDs in spite of impaired performance on the Game of Dice Task and executive dysfunctions. Furthermore, Bentivoglio et al. [97] recently reported that compared to PD patients without ICDs, PD patients with ICDs tend to lose more money and make more risky decisions on the task resembling the performance of pathological gamblers without PD [151, 152].

Djamshidian et al. [113] investigated decisionmaking under ambiguity in PD patients with and without ICDs using the Beads Task, which assesses reflective impulsivity under ambiguous conditions [209]. Overall, PD patients made more impulsive decisions than controls, reflecting a tendency in PD patients to make rapid decisions based on insufficient information [113]. A similar trend has been associated with DBS in STN. Frank et al. [44] showed that STN DBS interferes with the normal capacity to slow decisionmaking processes down when faced with ambiguous decision-making scenarios. In fact, they found that PD patients with DBS made more hasty decisions under high-conflict conditions [44].

\section{Decision-making under risk}

Decision-making under risk requires intact dorsolateral prefrontal cortex activity $[6,201]$ and can be assessed using the Game of Dice Task and the Cambridge Gambling Task, on which PD patients have shown poor performance [5, 201, 210, 211]. In particular, medicated patients seem to be impaired on these tasks, as suggested by Torta et al. [211] who found that patients receiving higher doses of dopaminergic medication performed worse and were more impulsive than patients receiving lower treatment doses.

Another way of measuring risky decision-making is by using the Balloon Analogue Risk Task [212], in which loss aversion has been associated with increased anterior cingulate cortex activity, whereas increased ventromedial prefrontal cortex activity has been associated with reward seeking [213]. In PD patients, this task seems to be modulated by dopaminergic medication, at least in PD patients with concurrent ICDs. Claassen et al. [51] recently demonstrated that dopamine agonists increased risk taking in PD patients with ICDs on this task, whereas no effect of dopamine agonists on risk taking was observed in PD patients without ICDs.

\section{Temporal discounting}

Temporal discounting refers to a preference towards more immediate rewards and a parallel devaluation of delayed rewards, a clinical finding very common in individuals suffering from ICDs and addictions. Just a few years ago, Voon et al. [75] linked dopamine agonist medication to an elevated delay discounting in PD patients with pathological gambling and compulsive buying relative to PD patients without ICDs. Furthermore, PD patients with ICDs revealed more working memory deficits than PD controls [75]. Interestingly, in another study Voon et al. [80] demonstrated increased impulsive decision-making in PD patients with compulsive buying and pathological gambling, but not in patients with binge eating or hypersexuality. Housden et al. [214] presented a similar finding in PD patients with comorbid ICDs indicating an inability to wait for a reward despite intact reward learning [149, 214]. Overall, these findings suggest that a tendency in PD patients with ICDs towards devaluation of delayed rewards, though differences across ICDs might exist. Furthermore, the disinhibited behavior appears to be enhanced by dopamine agonists and strongly associated with an elevated preference for immediate over future rewards [75, 80, 149, 214].

In summary, the aspects of cognition discussed above are highly relevant in PD since patients often suffer significant impairments as the disease progresses and following prolonged treatment. The issue of executive and decision-making dysfunctions associated with ICDs in PD is far from resolved, but it appears that a common feature for cognitive deficits associated with ICDs in PD involve disturbances in impulsivity, temporal discounting, cognitive flexibility, and reinforcement and reversal learning that is particularly related to the ventral striatum and the frontal cortex [13]. Nevertheless, inconsistent findings reinforce the need for additional studies to determine whether ICDs in PD are accompanied by further cognitive deficits and whether different ICDs are associated with different behavioral and cognitive profiles in PD.

\section{CONCLUSIONS AND PERSPECTIVES}

We have reviewed the literature from the past 12 years reporting ICDs in PD and conclude that a continuously growing number of studies support the concept of treatment-induced ICDs in PD. Both pharmacological and surgical therapies have been associated with the development of ICDs. Particularly, the direct $\mathrm{D}_{2} / \mathrm{D}_{3}$ dopamine agonists appear to be linked to this behavioral complication. Furthermore, we have argued that both the subthalamic nucleus and the nucleus accumbens play key roles in ICDs, potentially leading to 
serious consequences for the individual on financial, interpersonal, and cognitive levels. However, to fully understand why ICDs affect up to $15.5 \%$ of PD patients, it is not enough to consider the contributions of the dopaminergic system. Additional neurotransmitters need to be taken into account. We highlighted the impact of serotonin in the non-motor manifestations of PD and touched upon the role of opioids in addictive behaviors, since both neurotransmitters seem to be important mediators in reward processing and risk evaluation.

Despite an increasing interest in the field, we lack sufficient knowledge regarding therapy in ICD symptomatology in PD. Thus, there is a great need for future research to take a closer look at the functional neuroanatomy of ICDs and related cognitive deficits as evaluated by PET [74, 79, 82, 105, 107, 110, 111], SPECT [94, 95, 108], fMRI [45, 92, 96, 112], or MEG studies [215] in order to fully understand why PD patients appear to be at greater risk of developing ICDs than the general population. We have argued that both the orbitofrontal and anterior cingulate cortices and the ventral striatum are linked to impaired risk evaluation, which is mediated by dopamine agonists in PD patients suffering from comorbid ICDs. This serves as just one possible explanation of why dopamine agonists are among important risk factors for developing ICDs in PD $[45,51]$. Another possible explanation is related to the "overdose hypothesis" and attributes the cognitive deficits in PD patients with ICDs to the depleted caudate nucleus, and the dorsal striatum in general, altering the cognitive functions associated with the prefrontal cortex. This is then further compromised as the relatively intact ventral striatum in early PD is overdosed by dopaminergic treatment.

Likewise, an important step for future research is to assess how ICDs and other non-motor manifestations of PD affect the daily functioning and psychological well-being of the patients. Potentially, this could lead to faster identification of PD patients at risk for developing ICDs and improved management of adverse effects of treatment. A recent study demonstrated that in PD patients with ICDs symptom severity and related psychiatric disturbance improved following cognitive-behavioral therapy, unfortunately without relieving caregiver distress or burden markedly $[216,217]$. It is important in this regard to emphasize that the detection of ICDs relies very much on caregivers, who play an important role in the daily medical care and supervision of psychiatric symptoms following withdrawal of dopamine agonists [53, 98,
$216,218]$. Still, reduction of dopamine agonists is the primary strategy in managing ICDs in PD, but it is often associated with the development or worsening of depression, anxiety, or apathy, which have been found to occur in up to $19 \%$ of patient during dopamine agonist withdrawal [219]. Pharmacological management of ICDs in PD has received increasing attention in recent years and several different compounds have been scientifically tested. Among these are zonisamide [220] and donepezil [221], which are used to treat cognitive impairments and dementia in PD [222]. Also valproate, which is traditionally used to treat e.g. epilepsy, anorexia nervosa, anxiety, and bipolar disorders, has been shown effective in treating both pathological gambling in non-PD patients and ICDs in $\mathrm{PD}[34,223]$. Other possible candidates include selective serotonin reuptake inhibitors, at least in the subgroup of patients with ICD who displays comorbid depressive symptoms, the noradrenaline reuptake inhibitor atomoxetine, which is sometimes prescribed to patients with ADHD, since this compound leaves the ventral striatal dopamine system intact; and the opioid antagonist nalmefene [224, 225]. Undoubtedly, it is an important topic for future studies to investigate this in more detail, since mixed results have been reported so far [226, 227]. Additionally, future research should investigate whether dopamine agonist with an extended release are associated with ICDs as well, or whether these compounds could serve as an alternative to the more short-acting dopamine agonists in preventing the increased risk of developing ICDs in PD [226].

\section{SUPPLEMENTARY MATERIAL}

Supplementary Table 1: Extensive overview of 98 reports on ICDs in PD published between 2000-January 2013 including case reports, case series, case-control studies, experimental studies, and epidemiological studies. The table provides information on sample size, gender distribution, treatment, age, and PD duration.

Supplementary Table 2: Extensive overview of 98 reports on ICDs in PD published between 2000-January 2013 including case reports, case series, case-control studies, experimental studies, and epidemiological studies. The table provides information on prior history of ICDs, psychiatric symptoms, Hoehn \& Yahr, UPDRS, and additional information. The supplementary tables can be found here: http://dx.doi. org/10.3233/JPD-120165. 


\section{ACKNOWLEDGMENTS}

We thank Malene Flensborg Damholdt, Trine Gjerløff, and Anne Landau for commenting on a previous version of this review. We thank the Danish Agency for Science, Technology and Innovation for financial support, grant number 2102-07-0005.

\section{CONFLICT OF INTEREST}

The authors have no conflict of interest to report.

\section{REFERENCES}

[1] Parkinson J (1817) An Essay on the Shaking Palsy.

[2] Rowe JB, Hughes L, Ghosh BC, Eckstein D, Williams-Gray CH, Fallon S, Barker RA, \& Owen AM (2008) Parkinson's disease and dopaminergic therapy - differential effects on movement, reward and cognition. Brain, 131(Pt 8), 20942105.

[3] Cools R (2006) Dopaminergic modulation of cognitive function-implications for L-DOPA treatment in Parkinson's disease. Neurosci Biobehav Rev, 30(1), 1-23.

[4] Cools R, Frank MJ, Gibbs SE, Miyakawa A, Jagust W, \& D'Esposito M (2009) Striatal dopamine predicts outcomespecific reversal learning and its sensitivity to dopaminergic drug administration. J Neurosci, 29(5), 1538-1543.

[5] Brand M, Labudda K, Kalbe E, Hilker R, Emmans D, Fuchs G, Kessler J, \& Markowitsch HJ (2004) Decision-making impairments in patients with Parkinson's disease. Behav Neurol, 15(3-4), 77-85.

[6] Gleichgerrcht E, Ibanez A, Roca M, Torralva T, \& Manes F (2010) Decision-making cognition in neurodegenerative diseases. Nat Rev Neurol, 6(11), 611-623.

[7] Rodriguez-Oroz MC, Jahanshahi M, Krack P, Litvan I, Macias R, Bezard E, \& Obeso JA (2009) Initial clinical manifestations of Parkinson's disease: Features and pathophysiological mechanisms. Lancet Neurol, 8(12), 1128-1139.

[8] Weintraub D, \& Nirenberg MJ (2012) Impulse Control and Related Disorders in Parkinson's Disease. Neurodegener Dis, 11(2), 63-71.

[9] Tang J, Strafella AP (2012) The frontostriatal circuitry and behavioral complications in PD. Parkinsonism \& related disorders, 18(Suppl 1), S104-S106.

[10] Kano O, Ikeda K, Cridebring D, Takazawa T, Yoshii Y, \& Iwasaki Y (2011) Neurobiology of depression and anxiety in Parkinson's disease. Parkinsons Dis, 2011, 143547-

[11] Bonnet AM, Jutras MF, Czernecki V, Corvol JC, \& Vidailhet M (2012) Nonmotor symptoms in Parkinson's disease in 2012: Relevant clinical aspects. Parkinsons Dis, 2012, 198316-.

[12] Dubois B, \& Pillon B (1997) Cognitive deficits in Parkinson's disease. Journal of Neurology, 244(1), 2-8.

[13] Hirano S, Shinotoh H, \& Eidelberg D (2012) Functional brain imaging of cognitive dysfunction in Parkinson's disease. Journal of Neurology, Neurosurgery, and Psychiatry, 83(10), 963-969.

[14] Crossman AR (1990) A hypothesis on the pathophysiological mechanisms that underlie levodopa- or dopamine agonist-induced dyskinesia in Parkinson's disease: Implications for future strategies in treatment. Movement Disorders:
Official Journal of the Movement Disorder Society, 5(2), 100-108.

[15] APA APA (1994) Diagnostic and Statistical Manual of Mental Disorders, Fourth Revision (DSM-IV). Washington DC: American Psychiatric Association.

[16] Seedat S, Kesler S, Niehaus DJ, \& Stein DJ (2000) Pathological gambling behaviour: Emergence secondary to treatment of Parkinson's disease with dopaminergic agents. Depress Anxiety, 11(4), 185-186.

[17] Weintraub D, Papay K, \& Siderowf A (2013) Screening for impulse control symptoms in patients with de novo Parkinson disease: A case-control study. Neurology, 80(2), 176-180.

[18] Molina JA, Sainz-Artiga MJ, Fraile A, Jimenez-Jimenez FJ, Villanueva C, Orti-Pareja M, \& Bermejo F (2000) Pathologic gambling in Parkinson's disease: A behavioral manifestation of pharmacologic treatment? Mov Disord, 15(5), 869-872.

[19] Avanzi M, Uber E, \& Bonfa F (2004) Pathological gambling in two patients on dopamine replacement therapy for Parkinson's disease. Neurol Sci, 25(2), 98-101.

[20] Dodd ML, Klos KJ, Bower JH, Geda YE, Josephs KA, \& Ahlskog JE (2005) Pathological gambling caused by drugs used to treat Parkinson disease. Arch Neurol, 62(9), 13771381.

[21] Avanzi M, Baratti M, Cabrini S, Uber E, Brighetti G, \& Bonfa F (2006) Prevalence of pathological gambling in patients with Parkinson's disease. Mov Disord, 21(12), 2068-2072.

[22] Weintraub D, \& Potenza MN (2006) Impulse control disorders in Parkinson's disease. Curr Neurol Neurosci Rep, 6(4), 302-306.

[23] Moro E (2009) Impulse control disorders and subthalamic nucleus stimulation in Parkinson's disease: Are we jumping the gun? Eur J Neurol, 16(4), 440-441.

[24] Voon V, Hassan K, Zurowski M, de Souza M, Thomsen T, Fox S, Lang AE, \& Miyasaki J (2006) Prevalence of repetitive and reward-seeking behaviors in Parkinson disease. Neurology, 67(7), 1254-1257.

[25] Voon V, Thomsen T, Miyasaki JM, de Souza M, Shafro A, Fox SH, Duff-Canning S, Lang AE, \& Zurowski M (2007) Factors associated with dopaminergic drug-related pathological gambling in Parkinson disease. Arch Neurol, 64(2), 212-216.

[26] Weintraub D, Koester J, Potenza MN, Siderowf AD, Stacy M, Voon V, Whetteckey J, Wunderlich GR, \& Lang AE Impulse control disorders in Parkinson disease: A crosssectional study of 3090 patients. Arch Neurol, 67(5), 589595.

[27] Kim J, Kim M, Kwon DY, Seo WK, Kim JH, Baik JS, \& Koh SB (2012) Clinical characteristics of impulse control and repetitive behavior disorders in Parkinson's disease. Journal of neurology, 260(2), 429-437.

[28] Poletti M, \& Bonuccelli U (2012) Impulse control disorders in Parkinson' disease: The role of personality and cognitive status. Journal of Neurology, 259(11), 2269-2277.

[29] Potenza MN, Kosten TR, \& Rounsaville BJ (2001) Pathological gambling. JAMA, 286(2), 141-144.

[30] Dagher A, \& Robbins TW: (2009) Personality addiction, dopamine: Insights from Parkinson's disease. Neuron, 61(4), 502-510.

[31] Temel Y, Blokland A, Steinbusch HW, \& Visser-Vandewalle $\mathrm{V}$ (2005) The functional role of the subthalamic nucleus in cognitive and limbic circuits. Prog Neurobiol, 76(6), 393413. 
[32] Moum SJ, Price CC, Limotai N, Oyama G, Ward H, Jacobson C, Foote KD, \& Okun MS (2012) Effects of STN and GPi deep brain stimulation on impulse control disorders and dopamine dysregulation syndrome. PLoS One, 7(1), e29768.

[33] Romito LM, Raja M, Daniele A, Contarino MF, Bentivoglio AR, Barbier A, Scerrati M, \& Albanese A (2002) Transient mania with hypersexuality after surgery for high frequency stimulation of the subthalamic nucleus in Parkinson's disease. Movement disorders: Official Journal of the Movement Disorder Society, 17(6), 1371-1374.

[34] Sriram A, Ward HE, Hassan A, Iyer S, Foote KD, Rodriguez RL, McFarland NR, \& Okun MS (2012) Valproate as a treatment for dopamine dysregulation syndrome (DDS) in Parkinson's disease. Journal of Neurology, 260(2), 521527.

[35] Witjas T, Baunez C, Henry JM, Delfini M, Regis J, Cherif AA, Peragut JC, \& Azulay JP (2005) Addiction in Parkinson's disease: Impact of subthalamic nucleus deep brain stimulation. Mov Disord, 20(8), 1052-1055.

[36] Zahodne LB, Susatia F, Bowers D, Ong TL, Jacobson CEt, Okun MS, Rodriguez RL, Malaty IA, Foote KD, \& Fernandez HH (2011) Binge eating in Parkinson's disease: Prevalence, correlates and the contribution of deep brain stimulation. The Journal of Neuropsychiatry and Clinical Neurosciences, 23(1), 56-62.

[37] Smeding HM, Goudriaan AE, Foncke EM, Schuurman PR, Speelman JD, \& Schmand B (2007) Pathological gambling after bilateral subthalamic nucleus stimulation in Parkinson disease. J Neurol Neurosurg Psychiatry, 78(5), 517519 .

[38] Rodriguez-Oroz MC, Lopez-Azcarate J, Garcia-Garcia D, Alegre M, Toledo J, Valencia M, Guridi J, Artieda J, \& Obeso JA (2011) Involvement of the subthalamic nucleus in impulse control disorders associated with Parkinson's disease. Brain: A journal of neurology, 134(Pt 1), 36-49.

[39] Lim SY, O'Sullivan SS, Kotschet K, Gallagher DA, Lacey C, Lawrence AD, Lees AJ, O'Sullivan DJ, Peppard RF, Rodrigues JP, et al. (2009) Dopamine dysregulation syndrome, impulse control disorders and punding after deep brain stimulation surgery for Parkinson's disease. J Clin Neurosci, 16(9), 1148-1152.

[40] Knobel D, Aybek S, Pollo C, Vingerhoets FJ, \& Berney A (2008) Rapid resolution of dopamine dysregulation syndrome (DDS) after subthalamic DBS for Parkinson disease (PD): A case report. Cognitive and Behavioral Neurology: Official Journal of the Society for Behavioral and Cognitive Neurology, 21(3), 187-189.

[41] Bandini F, Primavera A, Pizzorno M, \& Cocito L (2007) Using STN DBS and medication reduction as a strategy to treat pathological gambling in Parkinson's disease. Parkinsonism Relat Disord, 13(6), 369-371.

[42] Halbig TD, Tse W, Frisina PG, Baker BR, Hollander E, Shapiro H, Tagliati M, Koller WC, \& Olanow CW (2009) Subthalamic deep brain stimulation and impulse control in Parkinson's disease. Eur J Neurol, 16(4), 493-497.

[43] Robert G, Drapier D, Verin M, Millet B, Azulay JP, \& Blin O (2009) Cognitive impulsivity in Parkinson's disease patients: Assessment and pathophysiology. Movement Disorders: Official Journal of the Movement Disorder Society, 24(16), 2316-2327.

[44] Frank MJ, Samanta J, Moustafa AA, \& Sherman SJ (2007) Hold your horses: Impulsivity, deep brain stimulation, and medication in parkinsonism. Science, 318(5854), 13091312.
[45] Voon V, Gao J, Brezing C, Symmonds M, Ekanayake V, Fernandez H, Dolan RJ, \& Hallett M (2011) Dopamine agonists and risk: Impulse control disorders in Parkinson's disease. Brain: A Journal of Neurology, 134(Pt 5), 1438-1446.

[46] Gallagher DA, O'Sullivan SS, Evans AH, Lees AJ, \& Schrag A (2007) Pathological gambling in Parkinson's disease: Risk factors and differences from dopamine dysregulation. An analysis of published case series. Mov Disord, 22(12), 1757 1763.

[47] Wu K, Politis M, \& Piccini P (2009) Parkinson disease and impulse control disorders: A review of clinical features, pathophysiology and management. Postgrad Med J, 85(1009), 590-596.

[48] Singh A, Kandimala G, Dewey RB Jr \& O'Suilleabhain P (2007) Risk factors for pathologic gambling and other compulsions among Parkinson's disease patients taking dopamine agonists. J Clin Neurosci, 14(12), 1178-1181.

[49] Delaney M, Leroi I, Simpson J, \& Overton PG (2012) Impulse control disorders in Parkinson's disease: A psychosocial perspective. J Clin Psychol Med Settings, 19(3), 338-346.

[50] Lee JY, Jeon BS, Kim HJ, \& Park SS (2012) Genetic variant of HTR2A associates with risk of impulse control and repetitive behaviors in Parkinson's disease. Parkinsonism \& related disorders, $\mathbf{1 8}(1), 76-78$.

[51] Claassen DO, van den Wildenberg WP, Ridderinkhof KR, Jessup CK, Harrison MB, Wooten GF, \& Wylie SA (2011) The risky business of dopamine agonists in Parkinson disease and impulse control disorders. Behav Neurosci, 125(4), 492-500.

[52] Cormier F, Muellner J, \& Corvol JC (2012) Genetics of impulse control disorders in Parkinson's disease. Journal of Neural Transmission, 120(4), 665-671.

[53] Weiss HD, Hirsch ES, Williams JR, Swearengin L, \& Marsh L (2010) Detection of impulse control disorders in Parkinson disease patients. The Neurologist, 16(6), 406-407.

[54] Joutsa J, Martikainen K, Vahlberg T, Voon V, \& Kaasinen V (2012) Impulse control disorders and depression in Finnish patients with Parkinson's disease. Parkinsonism \& Related Disorders, 18(2), 155-160.

[55] Joutsa J, Martikainen K, Vahlberg T, Kaasinen V (2012) Effects of dopamine agonist dose and gender on the prognosis of impulse control disorders in Parkinson's disease. Parkinsonism \& Related Disorders, 18(10), 1079-1083.

[56] Tokunaga N, Choudhury ME, Nishikawa N, Nagai M, Tujii T, Iwaki H, Kaneta M, \& Nomoto M (2012) Pramipexole upregulates dopamine receptor $\mathrm{D}(2)$ and $\mathrm{D}(3)$ expression in rat striatum. J Pharmacol Sci, 120(2), 133-137.

[57] Giovannoni G, O'Sullivan JD, Turner K, Manson AJ, \& Lees AJ (2000) Hedonistic homeostatic dysregulation in patients with Parkinson's disease on dopamine replacement therapies. J Neurol Neurosurg Psychiatry, 68(4), 423428.

[58] Gschwandtner U, Aston J, Renaud S, \& Fuhr P (2001) Pathologic gambling in patients with Parkinson's disease. Clin Neuropharmacol, 24(3), 170-172.

[59] Driver-Dunckley E, Samanta J, \& Stacy M (2003) Pathological gambling associated with dopamine agonist therapy in Parkinson's disease. Neurology, 61(3), 422-423.

[60] Kurlan R (2004) Disabling repetitive behaviors in Parkinson's disease. Mov Disord, 19(4), 433-437.

[61] Evans AH, Katzenschlager R, Paviour D, O'Sullivan JD, Appel S, Lawrence AD, \& Lees AJ (2004) Punding in Parkinson's disease: Its relation to the dopamine dysregulation syndrome. Mov Disord, 19(4), 397-405. 
[62] Klos KJ, Bower JH, Josephs KA, Matsumoto JY, \& Ahlskog JE (2005) Pathological hypersexuality predominantly linked to adjuvant dopamine agonist therapy in Parkinson's disease and multiple system atrophy. Parkinsonism Relat Disord, 11(6), 381-386

[63] Larner AJ (2006) Medical hazards of the internet: Gambling in Parkinson's disease. Mov Disord, 21(10), 1789.

[64] Ardouin C, Voon V, Worbe Y, Abouazar N, Czernecki V, Hosseini H, Pelissolo A, Moro E, Lhommee E, Lang AE et al. (2006): Pathological gambling in Parkinson's disease improves on chronic subthalamic nucleus stimulation. Mov Disord, 21(11), 1941-1946.

[65] Grosset KA, Macphee G, Pal G, Stewart D, Watt A, Davie J, \& Grosset DG (2006) Problematic gambling on dopamine agonists: Not such a rarity. Mov Disord, 21(12), 2206-2208.

[66] Drapier D, Drapier S, Sauleau P, Derkinderen P, Damier P, Allain H, Verin M, \& Millet B (2006) Pathological gambling secondary to dopaminergic therapy in Parkinson's disease. Psychiatry Res, 144(2-3), 241-244.

[67] Imamura A, Uitti RJ, \& Wszolek ZK (2006) Dopamine agonist therapy for Parkinson disease and pathological gambling. Parkinsonism Relat Disord, 12(8), 506-508.

[68] Voon V, \& Fox SH (2007) Medication-related impulse control and repetitive behaviors in Parkinson disease. Arch Neurol, 64(8), 1089-1096.

[69] Giladi N, Weitzman N, Schreiber S, Shabtai H, \& Peretz C (2007) New onset heightened interest or drive for gambling, shopping, eating or sexual activity in patients with Parkinson's disease: The role of dopamine agonist treatment and age at motor symptoms onset. J Psychopharmacol, 21(5), 501-506.

[70] Wong SH, Cowen Z, Allen EA, \& Newman PK (2007) Internet gambling and other pathological gambling in Parkinson's disease: A case series. Mov Disord, 22(4), 591593.

[71] McKeon A, Josephs KA, Klos KJ, Hecksel K, Bower JH, Michael Bostwick J, \& Eric Ahlskog J (2007) Unusual compulsive behaviors primarily related to dopamine agonist therapy in Parkinson's disease and multiple system atrophy. Parkinsonism Relat Disord, 13(8), 516-519.

[72] Ondo WG, \& Lai D (2008) Predictors of impulsivity and reward seeking behavior with dopamine agonists. Parkinsonism Relat Disord, 14(1), 28-32.

[73] Crockford D, Quickfall J, Currie S, Furtado S, Suchowersky O, \& El-Guebaly N (2008) Prevalence of problem and pathological gambling in Parkinson's disease. J Gambl Stud, 24(4), 411-422.

[74] Steeves TD, Miyasaki J, Zurowski M, Lang AE, Pellecchia G, Van Eimeren T, Rusjan P, Houle S, \& Strafella AP (2009) Increased striatal dopamine release in Parkinsonian patients with pathological gambling: A [11C] raclopride PET study. Brain, 132(Pt 5), 1376-1385.

[75] Voon V, Reynolds B, Brezing C, Gallea C, Skaljic M, Ekanayake V, Fernandez H, Potenza MN, Dolan RJ, \& Hallett $\mathbf{M}$ (2010) Impulsive choice and response in dopamine agonist-related impulse control behaviors. Psychopharmacology (Berl), 207(4), 645-659.

[76] Wylie SA, Ridderinkhof KR, Elias WJ, Frysinger RC, Bashore TR, Downs KE, van Wouwe NC, \& van den Wildenberg WP (2010) Subthalamic nucleus stimulation influences expression and suppression of impulsive behaviour in Parkinson's disease. Brain: A Journal of Neurology, 133( $\mathrm{Pt}$ 12), 3611-3624

[77] Vergani F, Landi A, Pirillo D, Cilia R, Antonini A, \& Sganzerla EP (2010) Surgical, medical, and hardware adverse events in a series of 141 patients undergoing subthalamic deep brain stimulation for Parkinson disease. World Neurosurg, 73(4), 338-344.

[78] Vitale C, Santangelo G, Trojano L, Verde F, Rocco M, Grossi D, \& Barone P (2011) Comparative neuropsychological profile of pathological gambling, hypersexuality, and compulsive eating in Parkinson's disease. Movement disorders: Official journal of the Movement Disorder Society, 26(5), 830-836.

[79] Evans AH, Pavese N, Lawrence AD, Tai YF, Appel S, Doder M, Brooks DJ, Lees AJ, \& Piccini P (2006) Compulsive drug use linked to sensitized ventral striatal dopamine transmission. Annals of Neurology, 59(5), 852-858.

[80] Voon V, Sohr M, Lang AE, Potenza MN, Siderowf AD, Whetteckey J, Weintraub D, Wunderlich GR, \& Stacy M (2011) Impulse control disorders in Parkinson disease: A multicenter case - control study. Annals of Neurology, 69(6), 986-996.

[81] Giugni JC, Tschopp L, Escalante V, \& Micheli F (2012) Dose-dependent impulse control disorders in piribedil overdose. Clinical Neuropharmacology, 35(1), 49-50.

[82] Ray NJ, Miyasaki JM, Zurowski M, Ko JH, Cho SS, Pellecchia G, Antonelli F, Houle S, Lang AE, \& Strafella AP (2012) Extrastriatal dopaminergic abnormalities of DA homeostasis in Parkinson's patients with medicationinduced pathological gambling: A [11C] FLB-457 and PET study. Neurobiol Dis, 48(3), 519-525.

[83] Limotai N, Oyama G, Go C, Bernal O, Ong T, Moum SJ, Bhidayasiri R, Foote KD, Bowers D, Ward H, et al. (2012) Addiction-like manifestations and Parkinson's disease: A large single center 9-year experience. Int J Neurosci, 122(3), 145-153.

[84] Avila A, Cardona X, Martin-Baranera M, Bello J, \& Sastre F (2011) Impulsive and compulsive behaviors in Parkinson's disease: A one-year follow-up study. J Neurol Sci, 310(1-2), 197-201.

[85] Auyeung M, Tsoi TH, Tang WK, Cheung CM, Lee CN, Li R, \& Yeung E (2011) Impulse control disorders in Chinese Parkinson's disease patients: The effect of ergot derived dopamine agonist. Parkinsonism \& Related Disorders, 17(8), 635-637.

[86] Leroi I, Ahearn DJ, Andrews M, McDonald KR, Byrne EJ, \& Burns A (2011) Behavioural disorders, disability and quality of life in Parkinson's disease. Age Ageing, 40(5), 614621.

[87] Biundo R, Formento-Dojot P, Facchini S, Vallelunga A, Ghezzo L, Foscolo L, Meneghello F, \& Antonini A (2011) Brain volume changes in Parkinson's disease and their relationship with cognitive and behavioural abnormalities. $J$ Neurol Sci, 310(1-2), 64-69.

[88] Spengos K, Grips E, Karachalios G, Tsivgoulis G, \& Papadimitriou G (2006) Reversible pathological gambling under treatment with pramipexole. Nervenarzt, 77(8), 958960.

[89] Mamikonyan E, Siderowf AD, Duda JE, Potenza MN, Horn S, Stern MB, \& Weintraub D (2008) Long-term follow-up of impulse control disorders in Parkinson's disease. Movement disorders: Official Journal of the Movement Disorder Society, 23(1), 75-80.

[90] Weintraub D, Siderowf AD, Potenza MN, Goveas J, Morales KH, Duda JE, Moberg PJ, \& Stern MB (2006) Association of dopamine agonist use with impulse control disorders in Parkinson disease. Archives of Neurology, 63(7), 969-973.

[91] Isaias IU, Siri C, Cilia R, De Gaspari D, Pezzoli G, \& Antonini A (2008) The relationship between impulsivity 
and impulse control disorders in Parkinson's disease. Movement Disorders: Official Journal of the Movement Disorder Society, 23(3), 411-415.

[92] Rao H, Mamikonyan E, Detre JA, Siderowf AD, Stern MB, Potenza MN, \& Weintraub D (2010) Decreased ventral striatal activity with impulse control disorders in Parkinson's disease. Movement Disorders: Official Journal of the Movement Disorder Society, 25(11), 1660-1669.

[93] Sensi M, Eleopra R, Cavallo MA, Sette E, Milani P, Quatrale R, Capone JG, Tugnoli V, Tola MR, Granieri E, et al. (2004) Explosive-aggressive behavior related to bilateral subthalamic stimulation. Parkinsonism Relat Disord, 10(4), 247-251.

[94] Cilia R, Cho SS, van Eimeren T, Marotta G, Siri C, Ko JH, Pellecchia G, Pezzoli G, Antonini A, \& Strafella AP (2011) Pathological gambling in patients with Parkinson's disease is associated with fronto-striatal disconnection: A path modeling analysis. Movement Disorders: Official Journal of the Movement Disorder Society, 26(2), 225-233.

[95] Cilia R, Ko JH, Cho SS, van Eimeren T, Marotta G, Pellecchia G, Pezzoli G, Antonini A, \& Strafella AP (2010) Reduced dopamine transporter density in the ventral striatum of patients with Parkinson's disease and pathological gambling. Neurobiol Dis, 39(1), 98-104.

[96] Voon V, Pessiglione M, Brezing C, Gallea C, Fernandez HH, Dolan RJ, \& Hallett M (2010) Mechanisms underlying dopamine-mediated reward bias in compulsive behaviors. Neuron, 65(1), 135-142.

[97] Bentivoglio AR, Baldonero E, Ricciardi L, De Nigris F, \& Daniele A (2012) Neuropsychological features of patients with Parkinson's disease and impulse control disorders. Neurological Sciences: Official Journal of the Italian Neurological Society and of the Italian Society of Clinical Neurophysiology.

[98] Pezzella FR, Colosimo C, Vanacore N, Di Rezze S, Chianese M, Fabbrini G, \& Meco G (2005) Prevalence and clinical features of hedonistic homeostatic dysregulation in Parkinson's disease. Mov Disord, 20(1), 77-81.

[99] Lim SY, Tan ZK, Ngam PI, Lor TL, Mohamed H, Schee JP, Tan AK, Goh JY, Ooi E, \& Soh PC (2011) Impulsivecompulsive behaviors are common in Asian Parkinson's disease patients: Assessment using the QUIP. Parkinsonism \& Related Disorders, 17(10), 761-764.

[100] Bastiaens J, Dorfman BJ, Christos PJ, \& Nirenberg MJ (2013) Prospective cohort study of impulse control disorders in Parkinson's disease. Movement Disorders: Official Journal of the Movement Disorder Society, 28(3), 327-333.

[101] Vitale C, Santangelo G, Erro R, Errico D, Manganelli F, Improta I, Moccia M, \& Barone P (2013) Impulse control disorders induced by rasagiline as adjunctive therapy for Parkinson's disease: Report of 2 cases. Parkinsonism \& Related Disorders, 19(4), 483-484.

[102] Hinnell C, Hulse N, Martin A, \& Samuel M (2011) Hypersexuality and compulsive over-eating associated with transdermal dopamine agonist therapy. Parkinsonism \& Related Disorders, 17(4), 295-296.

[103] Solla P, Cannas A, Marrosu MG, \& Marrosu F (2012) Dopaminergic-induced paraphilias associated with impulse control and related disorders in patients with Parkinson disease. Journal of Neurology, 259(12), 2752-2754.

[104] Perez-Lloret S, Rey MV, Fabre N, Ory F, Spampinato U, Brefel-Courbon C, Montastruc JL, \& Rascol O (2012) Prevalence and pharmacological factors associated with impulse-control disorder symptoms in patients with Parkinson disease. Clinical Neuropharmacology, 35(6), 261-265.
[105] Joutsa J, Martikainen K, Niemela S, Johansson J, Forsback S, Rinne JO, \& Kaasinen V (2012) Increased medial orbitofrontal [18F]fluorodopa uptake in Parkinsonian impulse control disorders. Movement Disorders: Official Journal of the Movement Disorder Society, 27(6), 778-782.

[106] Weintraub D, Xie S, Karlawish J, \& Siderowf A (2007) Differences in depression symptoms in patients with Alzheimer's and Parkinson's diseases: Evidence from the 15-item Geriatric Depression Scale (GDS-15). International Journal of Geriatric Psychiatry, 22(10), 1025-1030.

[107] van Eimeren T, Pellecchia G, Cilia R, Ballanger B, Steeves TD, Houle S, Miyasaki JM, Zurowski M, Lang AE, \& Strafella AP (2010) Drug-induced deactivation of inhibitory networks predicts pathological gambling in PD. Neurology, 75(19), 1711-1716.

[108] Cilia R, Siri C, Marotta G, Isaias IU, De Gaspari D, Canesi M, Pezzoli G, \& Antonini A (2008) Functional abnormalities underlying pathological gambling in Parkinson disease. Archives of Neurology, 65(12), 1604-1611.

[109] de Chazeron I, Llorca PM, Chereau-Boudet I, Blanc O, Perriot J, Ouchchane L, Ulla M, Debilly B, Derost P, \& Durif F (2011) Hypersexuality and pathological gambling in Parkinson's disease: A cross-sectional case-control study. Movement Disorders: Official Journal of the Movement Disorder Society, 26(11), 2127-2130.

[110] Wu K, O'Sullivan S, Politis M, Bose S, Lees A, \& Piccini $P$ (2010) Rewarding visual cues increase dopamine neurotransmission in Parkinspn's patients with impulse control disorders: A PET study. J Neurol Neurosurg Psychiatry, 81, e29-e30.

[111] O'Sullivan SS, Wu K, Politis M, Lawrence AD, Evans AH, Bose SK, Djamshidian A, Lees AJ, \& Piccini P (2011) Cue-induced striatal dopamine release in Parkinson's disease-associated impulsive-compulsive behaviours. Brain: A Journal of Neurology, 134(Pt 4), 969-978.

[112] Frosini D, Pesaresi I, Cosottini M, Belmonte G, Rossi C, Dell'Osso L, Murri L, Bonuccelli U, \& Ceravolo R (2010) Parkinson's disease and pathological gambling: Results from a functional MRI study. Movement Disorders: Official Journal of the Movement Disorder Society, 25(14), 24492453.

[113] Djamshidian A, O'Sullivan SS, Sanotsky Y, Sharman S, Matviyenko Y, Foltynie T, Michalczuk R, Aviles-Olmos I, Fedoryshyn L, Doherty KM et al. (2012) Decision making, impulsivity, and addictions: Do Parkinson's disease patients jump to conclusions? Movement Disorders: Official Journal of the Movement Disorder Society, 27(9), 1137-1145.

[114] Siri C, Cilia R, De Gaspari D, Canesi M, Meucci N, Zecchinelli AL, Pezzoli G, \& Antonini A (2010) Cognitive status of patients with Parkinson's disease and pathological gambling. Journal of Neurology, 257(2), 247-252.

[115] Kimber TE, Thompson PD, \& Kiley MA (2008) Resolution of dopamine dysregulation syndrome following cessation of dopamine agonist therapy in Parkinson's disease. Journal of Clinical Neuroscience: Official Journal of the Neurosurgical Society of Australasia, 15(2), 205-208.

[116] Tschopp L, Salazar Z, Gomez Botello MT, Roca CU, \& Micheli F (2010) Impulse control disorder and piribedil: Report of 5 cases. Clinical Neuropharmacology, 33(1), 11-13.

[117] Wingo TS, Evatt M, Scott B, Freeman A, \& Stacy M (2009) Impulse control disorders arising in 3 patients treated with rotigotine. Clinical Neuropharmacology, 32(2), 59-62. 
[118] Stefani A, Galati S, Brusa L, Pierantozzi M, Peppe A, \& Stanzione P (2010) Pathological gambling from dopamine agonist and deep brain stimulation of the nucleus tegmenti pedunculopontine. BMJ Case Rep, 2010.

[119] Fernández FM, \& González TM (2009) Pathological gambling and hypersexuality due to dopaminergic treatment in Parkinson's disease. Actas Esp Psiquiatr, 37(2), 118122.

[120] Cooper CA, Jadidian A, Paggi M, Romrell J, Okun MS, Rodriguez RL, \& Fernandez HH (2009) Prevalence of hypersexual behavior in Parkinson's disease patients: Not restricted to males and dopamine agonist use. Int J Gen Med, 2, 57-61.

[121] Bharmal A, Lu C, Quickfall J, Crockford D, \& Suchowersky O (2010) Outcomes of patients with Parkinson disease and pathological gambling. Can J Neurol Sci, 37(4), 473-477.

[122] Imamura A, Geda YE, Slowinski J, Wszolek ZK, Brown LA, \& Uitti RJ (2008) Medications used to treat Parkinson's disease and the risk of gambling. Eur J Neurol, 15(4), 350354.

[123] Santangelo G, Vitale C, Trojano L, Verde F, Grossi D, \& Barone P (2009) Cognitive dysfunctions and pathological gambling in patients with Parkinson's disease. Movement Disorders: Official Journal of the Movement Disorder Society, 24(6), 899-905.

[124] Kolla BP, Mansukhani MP, Barraza R, \& Bostwick JM (2010) Impact of dopamine agonists on compulsive behaviors: A case series of pramipexole-induced pathological gambling. Psychosomatics, 51(3), 271-273.

[125] Kenangil G, Ozekmekci S, Sohtaoglu M, \& Erginoz E (2010) Compulsive behaviors in patients with Parkinson's disease. The neurologist, 16(3), 192-195.

[126] Bonfanti AB, \& Gatto EM (2010) Kleptomania, an unusual impulsive control disorder in Parkinson's disease? Parkinsonism \& Related Disorders, 16(5), 358-359.

[127] Wicks P, \& MacPhee GJ (2009) Pathological gambling amongst Parkinson's disease and ALS patients in an online community (PatientsLikeMe.com). Movement Disorders: Official Journal of the Movement Disorder Society, 24(7), 1085-1088.

[128] Fan W, Ding H, Ma J, \& Chan P (2009) Impulse control disorders in Parkinson's disease in a Chinese population. Neurosci Lett, 465(1), 6-9.

[129] Lee JY, Kim JM, Kim JW, Cho J, Lee WY, Kim HJ, \& Jeon BS (2010) Association between the dose of dopaminergic medication and the behavioral disturbances in Parkinson disease. Parkinsonism \& Related Disorders, 16(3), 202207.

[130] Hassan A, Bower JH, Kumar N, Matsumoto JY, Fealey RD, Josephs KA, \& Ahlskog JE (2011) Dopamine agonisttriggered pathological behaviors: Surveillance in the PD clinic reveals high frequencies. Parkinsonism \& Related Disorders, 17(4), 260-264.

[131] Weintraub D, Sohr M, Potenza MN, Siderowf AD, Stacy M, Voon V, Whetteckey J, Wunderlich GR, \& Lang AE (2010) Amantadine use associated with impulse control disorders in Parkinson disease in cross-sectional study. Annals of Neurology, 68(6), 963-968.

[132] Serrano-Duenas M (2002) Chronic dopaminetic drug addiction and pathological gambling in patients with Parkinson's disease - presentation of four cases. German J Psychiatry, 5, 62-66.

[133] Cilia R, \& van Eimeren T (2011) Impulse control disorders in Parkinson's disease: Seeking a roadmap toward a better understanding. Brain Struct Funct, 216(4), 289-299.
[134] Tomlinson CL, Stowe R, Patel S, Rick C, Gray R, \& Clarke CE (2010) Systematic review of levodopa dose equivalency reporting in Parkinson's disease. Movement Disorders: Official Journal of the Movement Disorder Society, 25(15), 2649-2653.

[135] Mallet L, Schupbach M, N'Diaye K, Remy P, Bardinet E, Czernecki V, Welter ML, Pelissolo A, Ruberg M, Agid Y, et al. (2007) Stimulation of subterritories of the subthalamic nucleus reveals its role in the integration of the emotional and motor aspects of behavior. Proc Natl Acad Sci U S A, 104(25), 10661-10666.

[136] Rogers RD, Wielenberg B, Wojtecki L, Elben S, CampbellMeiklejohn D, \& Schnitzler A (2011) Deep brain stimulation of the subthalamic nucleus transiently enhances losschasing behaviour in patients with Parkinson's disease. Exp Neurol, 231(1), 181-189.

[137] Funkiewiez A, Ardouin C, Caputo E, Krack P, Fraix V, Klinger H, Chabardes S, Foote K, Benabid AL, \& Pollak $\mathrm{P}$ (2004) Long term effects of bilateral subthalamic nucleus stimulation on cognitive function, mood, and behaviour in Parkinson's disease. Journal of Neurology, Neurosurgery, and Psychiatry, 75(6), 834-839.

[138] Volkmann J, Daniels C, \& Witt K (2010) Neuropsychiatric effects of subthalamic neurostimulation in Parkinson disease. Nat Rev Neurol, 6(9), 487-498.

[139] Adam R, Leff A, Sinha N, Turner C, Bays P, Draganski B, \& Husain M (2012) Dopamine reverses reward insensitivity in apathy following globus pallidus lesions. Cortex, 49(5), 1292-1303.

[140] Leroi I, Andrews M, McDonald K, Harbishettar V, Elliott R, Byrne EJ, \& Burns A (2012) Apathy and impulse control disorders in Parkinson's disease: A direct comparison. Parkinsonism \& Related Disorders, 18(2), 198-203.

[141] Ahearn DJ, McDonald K, Barraclough M, \& Leroi I (2012) An exploration of apathy and impulsivity in Parkinson disease. Curr Gerontol Geriatr Res, 2012, 390701.

[142] Jenkinson N, Nandi D, Muthusamy K, Ray NJ, Gregory R, Stein JF, \& Aziz TZ (2009) Anatomy, physiology, and pathophysiology of the pedunculopontine nucleus. Movement Disorders: Official Journal of the Movement Disorder Society, 24(3), 319-328.

[143] Androulidakis AG, Mazzone P, Litvak V, Penny W, Dileone M, Gaynor LM, Tisch S, Di Lazzaro V, \& Brown P (2008) Oscillatory activity in the pedunculopontine area of patients with Parkinson's disease. Exp Neurol, 211(1), 59-66.

[144] Thevathasan W, Silburn PA, Brooker H, Coyne TJ, Khan S, Gill SS, Aziz TZ, \& Brown P (2010) The impact of low-frequency stimulation of the pedunculopontine nucleus region on reaction time in parkinsonism. Journal of Neurology, Neurosurgery, and Psychiatry, 81(10), 1099-1104.

[145] Okada K, Toyama K, Inoue Y, Isa T, \& Kobayashi Y (2009) Different pedunculopontine tegmental neurons signal predicted and actual task rewards. The Journal of Neuroscience: The Official Journal of the Society for Neuroscience, 29(15), 4858-4870.

[146] Kobayashi Y, \& Okada K (2007) Reward prediction error computation in the pedunculopontine tegmental nucleus neurons. Ann N Y Acad Sci, 1104, 310-323.

[147] Volkow ND, Wang GJ, Telang F, Fowler JS, Logan J, Childress AR, Jayne M, Ma Y, \& Wong C (2006) Cocaine cues and dopamine in dorsal striatum: Mechanism of craving in cocaine addiction. The Journal of neuroscience: The Official Journal of the Society for Neuroscience, 26(24), 6583-6588.

[148] Cools R, Lewis SJ, Clark L, Barker RA, \& Robbins TW (2007) L-DOPA disrupts activity in the nucleus accumbens 
during reversal learning in Parkinson's disease. Neuropsychopharmacology: Official Publication of the American College of Neuropsychopharmacology, 32(1), 180-189.

[149] Voon V, \& Dalley JW (2011) Parkinson disease: Impulsive choice-Parkinson disease and dopaminergic therapy. Nat Rev Neurol, 7(10), 541-542.

[150] Graef S, Biele G, Krugel LK, Marzinzik F, Wahl M, Wotka J, Klostermann F, \& Heekeren HR (2010) Differential influence of levodopa on reward-based learning in Parkinson's disease. Front Hum Neurosci, 4, 169.

[151] Linnet J, Moller A, Peterson E, Gjedde A, \& Doudet D (2011) Dopamine release in ventral striatum during Iowa Gambling Task performance is associated with increased excitement levels in pathological gambling. Addiction, 106(2), 383-390.

[152] Linnet J, Peterson E, Doudet DJ, Gjedde A, \& Moller A (2010) Dopamine release in ventral striatum of pathological gamblers losing money. Acta Psychiatr Scand, 122(4), 326333.

[153] Peterson E, Moller A, Doudet DJ, Bailey CJ, Hansen KV, Rodell A, Linnet J, \& Gjedde A (2010) Pathological gambling: Relation of skin conductance response to dopaminergic neurotransmission and sensation-seeking. Eur Neuropsychopharmacol, 20(11), 766-775.

[154] de Ruiter MB, Veltman DJ, Goudriaan AE, Oosterlaan J, Sjoerds Z, \& van den Brink W (2009) Response perseveration and ventral prefrontal sensitivity to reward and punishment in male problem gamblers and smokers. Neuropsychopharmacology: Official Publication of the American College of Neuropsychopharmacology, 34(4), 1027-1038.

[155] Reuter J, Raedler T, Rose M, Hand I, Glascher J, \& Buchel C (2005) Pathological gambling is linked to reduced activation of the mesolimbic reward system. Nature Neuroscience, 8(2), $147-148$.

[156] Nader MA, Morgan D, Gage HD, Nader SH, Calhoun TL, Buchheimer N, Ehrenkaufer R, \& Mach RH (2006) PET imaging of dopamine D2 receptors during chronic cocaine self-administration in monkeys. Nature Neuroscience, 9(8), 1050-1056.

[157] Volkow ND, Fowler JS, \& Wang GJ (2002) Role of dopamine in drug reinforcement and addiction in humans: Results from imaging studies. Behav Pharmacol, 13(5-6), 355-366.

[158] Dalley JW, Fryer TD, Brichard L, Robinson ES, Theobald DE, Laane K, Pena Y, Murphy ER, Shah Y, Probst K, et al. (2007) Nucleus accumbens D2/3 receptors predict trait impulsivity and cocaine reinforcement. Science, $\mathbf{3 1 5}(5816)$, 1267-1270.

[159] Volkow ND, Wang GJ, Telang F, Fowler JS, Thanos PK, Logan J, Alexoff D, Ding YS, Wong C, Ma Y, et al. (2008) Low dopamine striatal D2 receptors are associated with prefrontal metabolism in obese subjects: Possible contributing factors. Neuroimage, 42(4), 1537-1543.

[160] Wang GJ, Volkow ND, Logan J, Pappas NR, Wong CT, Zhu W, Netusil N, \& Fowler JS (2001) Brain dopamine and obesity. Lancet, 357(9253), 354-357.

[161] Volkow ND, Fowler JS, Wang GJ, \& Goldstein RZ (2002) Role of dopamine, the frontal cortex and memory circuits in drug addiction: Insight from imaging studies. Neurobiol Learn Mem, 78(3), 610-624.

[162] Joutsa J, Johansson J, Niemela S, Ollikainen A, Hirvonen MM, Piepponen P, Arponen E, Alho H, Voon V, Rinne JO, et al. (2012) Mesolimbic dopamine release is linked to symptom severity in pathological gambling. Neuroimage, 60(4), 1992-1999.
[163] Kringelbach ML, \& Berridge KC (2010) The functional neuroanatomy of pleasure and happiness. Discov Med, 9(49), 579-587.

[164] Berridge KC (2007) The debate over dopamine's role in reward: The case for incentive salience. Psychopharmacology (Berl), 191(3), 391-431.

[165] Everitt BJ, \& Robbins TW (2005) Neural systems of reinforcement for drug addiction: From actions to habits to compulsion. Nature Neuroscience, 8(11), 1481-1489.

[166] Haber SN, \& Knutson B (2010) The reward circuit: Linking primate anatomy and human imaging. Neuropsychopharmacology: Official Publication of the American College of Neuropsychopharmacology, 35(1), 4-26.

[167] Voon V, Mehta AR, \& Hallett M (2011) Impulse control disorders in Parkinson's disease: Recent advances. Current Opinion in Neurology, 24(4), 324-330.

[168] Di Matteo V, Pierucci M, Esposito E, Crescimanno G, Benigno A, \& Di Giovanni G (2008) Serotonin modulation of the basal ganglia circuitry: Therapeutic implication for Parkinson's disease and other motor disorders. Prog Brain Res, 172, 423-463.

[169] Cools R (2008) Role of dopamine in the motivational and cognitive control of behavior. Neuroscientist, 14(4), 381395

[170] Cools R, Nakamura K, \& Daw ND (2011) Serotonin and dopamine: Unifying affective, activational, and decision functions. Neuropsychopharmacology: Official Publication of the American College of Neuropsychopharmacology, 36(1), 98-113.

[171] Rogers RD (2011) The roles of dopamine and serotonin in decision making: Evidence from pharmacological experiments in humans. Neuropsychopharmacology: Official Publication of the American College of Neuropsychopharmacology, 36(1), 114-132.

[172] Robinson ES, Dalley JW, Theobald DE, Glennon JC, Pezze MA, Murphy ER, \& Robbins TW (2008) Opposing roles for 5-HT2A and 5-HT2C receptors in the nucleus accumbens on inhibitory response control in the 5-choice serial reaction time task. Neuropsychopharmacology, 33(10), 2398-2406.

[173] Homberg JR (2012) Serotonin and decision making processes. Neuroscience and Biobehavioral Reviews, 36(1), 218-236.

[174] Kirby LG, Zeeb FD, \& Winstanley CA (2011) Contributions of serotonin in addiction vulnerability. Neuropharmacology, 61(3), 421-432.

[175] Macoveanu J, Rowe JB, Hornboll B, Elliott R, Paulson OB Knudsen GM, \& Siebner HR (2012) Playing it safe but losing anyway-Serotonergic signaling of negative outcomes in dorsomedial prefrontal cortex in the context of risk-aversion. Eur Neuropsychopharmacol, in press.

[176] Miyazaki K, Miyazaki KW, \& Doya K (2012) The role of serotonin in the regulation of patience and impulsivity. $\mathrm{Mol}$ Neurobiol, 45(2), 213-224.

[177] Campbell-Meiklejohn D, Wakeley J, Herbert V, Cook J, Scollo P, Ray MK, Selvaraj S, Passingham RE, Cowen P, \& Rogers RD (2011) Serotonin and dopamine play complementary roles in gambling to recover losses. Neuropsychopharmacology: Official Publication of the American College of Neuropsychopharmacology, 36(2), 402-410.

[178] Long AB, Kuhn CM, \& Platt ML (2009) Serotonin shapes risky decision making in monkeys. Soc Cogn Affect Neurosci, 4(4), 346-356.

[179] Chung SK, You IH, Cho GH, Chung GH, Shin YC, Kim DJ, \& Choi SW (2009) Changes of functional MRI findings 
in a patient whose pathological gambling improved with fluvoxamine. Yonsei Med J, 50(3), 441-444.

[180] Raja M, \& Bentivoglio AR (2012) Impulsive and compulsive behaviors during dopamine replacement treatment in Parkinson's Disease and other disorders. Curr Drug Saf, 7(1), 63-75.

[181] Kringelbach ML, \& Rolls ET (2003) Neural correlates of rapid reversal learning in a simple model of human social interaction. Neuroimage, 20(2), 1371-1383.

[182] Clark L, Cools R, \& Robbins TW (2004) The neuropsychology of ventral prefrontal cortex: Decision-making and reversal learning. Brain and Cognition, 55(1), 41-53.

[183] Levin BE, Tomer R, \& Rey GJ (1992) Cognitive impairments in Parkinson's disease. Neurol Clin, 10(2), 471485.

[184] Brown RG, \& Marsden CD (1990) Cognitive function in Parkinson's disease: From description to theory. Trends Neurosci, 13(1), 21-29.

[185] Poletti M, Cavedini P, \& Bonuccelli U (2011) Iowa gambling task in Parkinson's disease. J Clin Exp Neuropsychol, 33(4), 395-409.

[186] Poletti M, \& Bonuccelli U (2012) Orbital and ventromedial prefrontal cortex functioning in Parkinson's disease: Neuropsychological evidence. Brain and Cognition, 79(1), 23-33.

[187] Carter CS, \& van Veen V (2007) Anterior cingulate cortex and conflict detection: An update of theory and data. Cogn Affect Behav Neurosci, 7(4), 367-379.

[188] Konishi S, Nakajima K, Uchida I, Kameyama M, Nakahara K, Sekihara K, \& Miyashita Y (1998) Transient activation of inferior prefrontal cortex during cognitive set shifting. Nature Neuroscience, 1(1), 80-84.

[189] Monchi O, Petrides M, Petre V, Worsley K, \& Dagher A (2001) Wisconsin Card Sorting revisited: Distinct neural circuits participating in different stages of the task identified by event-related functional magnetic resonance imaging. The Journal of neuroscience: The official journal of the Society for Neuroscience, 21(19), 7733-7741.

[190] Frank MJ, Loughry B, \& O'Reilly RC (2001) Interactions between frontal cortex and basal ganglia in working memory: A computational model. Cogn Affect Behav Neurosci, 1(2), 137-160.

[191] Raskin SA, Borod JC, \& Tweedy J (1990) Neuropsychological aspects of Parkinson's disease. Neuropsychol Rev, 1(3), 185-221.

[192] Pillon B, Deweer B, Vidailhet M, Bonnet AM, Hahn-Barma V, \& Dubois B (1998) Is impaired memory for spatial location in Parkinson's disease domain specific or dependent on 'strategic' processes? Neuropsychologia, 36(1), 1-9.

[193] Stocchi F, \& Brusa L (2000) Cognition and emotion in different stages and subtypes of Parkinson's disease. Journal of Neurology, 247(Suppl 2), II114-II121.

[194] Pagonabarraga J, Garcia-Sanchez C, Llebaria G, PascualSedano B, Gironell A, \& Kulisevsky J (2007) Controlled study of decision-making and cognitive impairment in Parkinson's disease. Mov Disord, 22(10), 1430-1435.

[195] Flensborg Damholdt M, Shevlin M, Borghammer P, Larsen L, \& Ostergaard K (2012) Clinical heterogeneity in Parkinson's disease revisited: A latent profile analysis. Acta Neurologica Scandinavica, 125(5), 311-318.

[196] Gescheidt T, Czekoova K, Urbanek T, Marecek R, Mik M, Kubikova R, Telecka S, Andrlova H, Husarova I, \& Bares M (2012), Gambling Task in patients with earlyonset Parkinson's disease: Strategy analysis. Neurological sciences: Official journal of the Italian Neurological Soci- ety and of the Italian Society of Clinical Neurophysiology, 33(6), 1329-1335.

[197] Swainson R, Rogers RD, Sahakian BJ, Summers BA, Polkey CE, \& Robbins TW (2000) Probabilistic learning and reversal deficits in patients with Parkinson's disease or frontal or temporal lobe lesions: Possible adverse effects of dopaminergic medication. Neuropsychologia, 38(5), 596-612.

[198] Cools R, Altamirano L, \& D’Esposito M (2006) Reversal learning in Parkinson's disease depends on medication status and outcome valence. Neuropsychologia, 44(10), 16631673.

[199] Cools R, Barker RA, Sahakian BJ, \& Robbins TW (2001) Enhanced or impaired cognitive function in Parkinson's disease as a function of dopaminergic medication and task demands. Cereb Cortex, 11(12), 1136-1143.

[200] Humphries MD, Khamassi M, \& Gurney K (2012) Dopaminergic Control of the Exploration-Exploitation Trade-Off via the Basal Ganglia. Front Neurosci, 6, 9.

[201] Euteneuer F, Schaefer F, Stuermer R, Boucsein W, Timmermann L, Barbe MT, Ebersbach G, Otto J, Kessler J, \& Kalbe E (2009) Dissociation of decision-making under ambiguity and decision-making under risk in patients with Parkinson's disease: A neuropsychological and psychophysiological study. Neuropsychologia, 47(13), 2882-2890.

[202] Bechara A, Damasio AR, Damasio H, \& Anderson SW (1994) Insensitivity to future consequences following damage to human prefrontal cortex. Cognition, 50(1-3), 7-15.

[203] Bechara A, Damasio H, Damasio AR, \& Lee GP (1999) Different contributions of the human amygdala and ventromedial prefrontal cortex to decision-making. The Journal of Neuroscience: The Official Journal of the Society for Neuroscience, 19(13), 5473-5481.

[204] Mimura M, Oeda R, \& Kawamura M (2006) Impaired decision-making in Parkinson's disease. Parkinsonism \& Related Disorders, 12(3), 169-175.

[205] Ibarretxe-Bilbao N, Junque C, Tolosa E, Marti MJ, Valldeoriola F, Bargallo N, \& Zarei M (2009) Neuroanatomical correlates of impaired decision-making and facial emotion recognition in early Parkinson's disease. Eur J Neurosci, 30(6), 1162-1171.

[206] Kobayakawa M, Koyama S, Mimura M, \& Kawamura M (2008) Decision making in Parkinson's disease: Analysis of behavioral and physiological patterns in the Iowa gambling task. Movement Disorders: Official Journal of the Movement Disorder Society, 23(4), 547-552.

[207] Perretta JG, Pari G, \& Beninger RJ (2005) Effects of Parkinson disease on two putative nondeclarative learning tasks: Probabilistic classification and gambling. Cogn Behav Neurol, 18(4), 185-192.

[208] Rossi M, Gerschcovich ER, de Achaval D, Perez-Lloret S, Cerquetti D, Cammarota A, Ines Nouzeilles M, Fahrer R, Merello M, \& Leiguarda R (2010) Decision-making in Parkinson's disease patients with and without pathological gambling. Eur J Neurol, 17(1), 97-102.

[209] Phillips LD, \& Edwards W (1966) Conservatism in a simple probability inference task. J Exp Psychol, 72(3), 346-354.

[210] Cools R, Barker RA, Sahakian BJ, \& Robbins TW (2003) L-Dopa medication remediates cognitive inflexibility, but increases impulsivity in patients with Parkinson's disease. Neuropsychologia, 41(11), 1431-1441.

[211] Torta DM, Castelli L, Zibetti M, Lopiano L, \& Geminiani $\mathrm{G}$ (2009) On the role of dopamine replacement therapy in decision-making, working memory, and reward in Parkinson's disease: Does the therapy-dose matter? Brain and cognition, 71(2), 84-91. 
[212] Lejuez CW, Read JP, Kahler CW, Richards JB, Ramsey SE, Stuart GL, Strong DR, \& Brown RA (2002) Evaluation of a behavioral measure of risk taking: The Balloon Analogue Risk Task (BART). J Exp Psychol Appl, 8(2), 75-84.

[213] Fukunaga R, Brown JW, \& Bogg T (2012) Decision making in the Balloon Analogue Risk Task (BART): Anterior cingulate cortex signals loss aversion but not the infrequency of risky choices. Cogn Affect Behav Neurosci, 12(3), 479-490.

[214] Housden CR, O'Sullivan SS, Joyce EM, Lees AJ, \& Roiser JP (2010) Intact reward learning but elevated delay discounting in Parkinson's disease patients with impulsive-compulsive spectrum behaviors. Neuropsychopharmacology: Official Publication of the American College of Neuropsychopharmacology, 35(11), 2155-2164.

[215] Rømer Thomsen K, Joensson M, Lou HC, Møller A, Gross J, Kringelbach ML, \& Changeux JP (2013) Altered paralimbic interaction in behavioral addiction. PNAS, 110(12), 47444749.

[216] Macphee GJ, \& Carson A (2013) Impulse control disorders in Parkinson disease: Is cognitive-behavioral therapy worth a wager? Neurology.

[217] Okai D, Askey-Jones S, Samuel M, O’Sullivan SS, Chaudhuri KR, Martin A, Mack J, Brown RG, \& David AS (2013) Trial of CBT for impulse control behaviors affecting Parkinson patients and their caregivers. Neurology, 80(9), 792-799.

[218] Leroi I, Harbishettar V, Andrews M, McDonald K, Byrne EJ, \& Burns A (2012) Carer burden in apathy and impulse control disorders in Parkinson's disease. International Journal of Geriatric Psychiatry, 27(2), 160-166.
[219] Rabinak CA, \& Nirenberg MJ (2010) Dopamine agonist withdrawal syndrome in Parkinson disease. Archives of Neurology, 67(1), 58-63.

[220] Bermejo PE, Ruiz-Huete C, \& Anciones B (2010) Zonisamide in managing impulse control disorders in Parkinson's disease. Journal of Neurology, 257(10), 16821685 .

[221] Ivanco LS, \& Bohnen NI (2005) Effects of donepezil on compulsive hypersexual behavior in Parkinson disease: A single case study. Am J Ther, 12(5), 467-468.

[222] Jankovic J, \& Poewe W (2012) Therapies in Parkinson's disease. Current Opinion in Neurology, 25(4), 433-447.

[223] Hicks CW, Pandya MM, Itin I, \& Fernandez HH (2011) Valproate for the treatment of medication-induced impulsecontrol disorders in three patients with Parkinson's disease. Parkinsonism \& Related Disorders, 17(5), 379-381.

[224] Baarendse PJ, \& Vanderschuren LJ (2012) Dissociable effects of monoamine reuptake inhibitors on distinct forms of impulsive behavior in rats. Psychopharmacology (Berl), 219(2), 313-326.

[225] Grant JE, Odlavg BL, Potenza MN, Hollander E, \& Won Kim S (2010) Nalmafene in the treatment of pathological gambling: Multicentre, double-blind, placebo-controlled study. BJPsych, 197, 330-331.

[226] Muller T (2012) Drug therapy in patients with Parkinson's disease. Transl Neurodegener, 1(1), 10.

[227] Connolly BS, \& Fox SH (2012) Drug treatments for the neuropsychiatric complications of Parkinson's disease. Expert Rev Neurother, 12(12), 1439-1449. 